\title{
Estimating the Peace Dividend: The Impact of Violence on House Prices in Northern Ireland*
}

\author{
Timothy Besley \\ LSE and CIFAR
}

Hannes Mueller

IAE/CSIC

May 2009

\author{
The Suntory Centre \\ Suntory and Toyota International Centres for \\ Economics and Related Disciplines \\ London School of Economics and Political Science \\ Houghton Street \\ London WC2A 2AE
}

EOPP 11

\footnotetext{
* We are grateful for comments and insights to members of the CIFAR program on Institutions, Organizations and Growth; participants in the CEPR workshop on Conflicts, Globalization and Development; and seminar participants at Columbia University, the WZB and UAB. Besley also thanks the ESRC and CIFAR for financial support.
} 


\begin{abstract}
This paper exploits data on the pattern of violence across regions and over time to estimate the impact of the peace process in Northern Ireland on house prices. We begin with a linear model that estimates the average treatment effect of a conflictrelated killing on house prices - showing a negative correlation between house prices and killings. We then develop an approach based on an economic model where the parameters of the statistical process are estimated for a Markov switching model where conflict and peace are treated as a latent state. From this, we are able to construct a measure of the discounted number of killings which is updated in the light of actual killings. This model naturally suggests a heterogeneous effect of killings across space and time which we use to generate estimates of the peace dividend. The economic model suggests a somewhat different pattern of estimates to the linear model. We also show that there is some evidence of spillover effects of violence in adjacent regions.
\end{abstract}

Keywords: Peace Dividend, Northern Ireland, Conflict, Housing Price, Markov Chain

JEL Classification: D74, 016, P16. 
This series is published by the Economic Organisation and Public Policy Programme (EOPP) located within the Suntory and Toyota International Centres for Economics and Related Disciplines (STICERD) at the London School of Economics and Political Science. This new series is an amalgamation of the Development Economics Discussion Papers and the Political Economy and Public Policy Discussion Papers. The programme was established in October 1998 as a successor to the Development Economics Research Programme. The work of the programme is mainly in the fields of development economics, public economics and political economy. It is directed by Maitreesh Ghatak. Oriana Bandiera, Robin Burgess, and Andrea Prat serve as codirectors, and associated faculty consist of Timothy Besley, Jean-Paul Faguet, Henrik Kleven, Valentino Larcinese, Gerard Padro i Miquel, Torsten Persson, Nicholas Stern, and Daniel M. Sturm. Further details about the programme and its work can be viewed on our web site at http://sticerd.lse.ac.uk/research/eopp.

Our Discussion Paper series is available to download at:

http://sticerd.lse.ac.uk/_new/publications/series.asp?prog=EOPP

For any other information relating to this series please contact Leila Alberici on:

Telephone: UK+20 79556674

Fax: $\quad$ UK+20 $\quad$ : $\quad$ (a556951

Email: $\quad$ l.alberici @lse.ac.uk

(c) The authors. All rights reserved. Short sections of text, not to exceed two paragraphs, may be quoted without explicit permission provided that full credit, including (C) notice, is given to the source. 


\section{Introduction}

Conflict in Ireland has a long history. Even after the Republic of Ireland was created as an independent state in 1920, the status of the mainly Protestant north remained contested. From the late 1960's a violent conflict flared up which claimed around 3500 lives. Only more than two decades later, from 1993 onwards, emerged a peace process which, while initially fragile, culminated in a cessation of violence and a return to devolved government by 2007. The conflict was a major source of social and economic dislocation. But, as peace took hold, this has begun to be repaired.

The extensive literature on conflict in economics emphasizes the economic costs of fighting - both in discouraging investment and in out-migration from areas of intense conflict. Even during the height of the conflict in Northern Ireland, violence was not uniform. For example, Belfast - the capital city of the province of Northern Ireland - was particularly hard hit. Looking for economic consequences of the peace process, we would therefore expect benefits to be concentrated among areas where violence was most prevalent. To this end, this paper studies one economic aspect of the peace process and the dividend that it brought to residents of Northern Ireland - the impact on house prices. Houses are assets whose prices reflect the present and future expected attractiveness of living in an area. We therefore expect the current level of violence to have a direct effect on prices in so far as it contains relevant information about the future. This paper exploits within-region variability in violence and house prices over time. Having such variation is rare in studies of the economic consequences of conflict.

Our specific measure of violence here is conflict related deaths. These have the advantage of being well-documented in this particular instance by Sutton (1994) and the Conflict Archive on the Internet (CAIN). Importantly, we are able to match the location of the death to a region within Northern Ireland. We then look for a peace dividend in the form of increased house prices in response to a reduction in killing. For this we use a quarterly house price index for 11 regions of Northern Ireland for 1984q1 to 2008q4.

One aspect of the paper is to pursue an interpretation of the findings through the lens of an economic model of house prices. We argue that the interpretation of a correlation between conflict and housing prices hinges on a theory of the violence generating process. To that end we assume that killings are informative about an unobserved state - peace or conflict - and that during the period following the beginning of the peace process, 
citizens were using information about killings to update their views about the likelihood of being in that state. We then estimate the parameters of the Markov process generating transition probabilities across states. Our theory can be used to construct an estimate of the expected present discounted value of deaths in each region as a function of the history. This creates a "treatment effect" of a killing in a particular region in a given quarter which is naturally heterogeneous - depending on the overall pattern of killing in that region. This model is shown to explain house price changes and predicts a pattern of changes in house prices across regions that is rather different from fitting OLS. In particular, it suggests in line with intuition that there are bigger peace dividends in regions of Northern Ireland where violence was more prevalent, i.e. more severe and persistent.

We assess the robustness of our findings in a number of ways. We also look for spillover effects across regions. Here, the results suggest that violence in Belfast actually increased house prices in adjacent areas - consistent with the data on relative changes in population over the period that we study.

The remainder of the paper is structured as follows. In the next section, we give some background to the Northern Irish conflict. Section three relates our paper to the existing literature. In section four, we discuss data and present some preliminary OLS results. Section five develops a model of house prices and a statistical model of the peace process. We then explain how this can be implemented empirically. Section 6 presents results, including a number of robustness checks. Section seven concludes. Some details about the data and the method are in the Appendix.

\section{Background}

From the 17th century onwards, the British consolidated their rule over Ireland. However, it was mainly in the nineteenth century that the struggle for reform began. The status of Ireland proved to be a fractious issue in U.K. politics over this century with the issue of Irish home rule splitting the Liberal party at the end of the late nineteenth century. Northern Ireland was created after the Government of Ireland Act of 1920 which granted the rest of Ireland independence from the U.K.. From 1922 onwards, Northern Ireland separated from the south, now the Republic of Ireland, and became a self-governing province of the U.K.. However, the long-term status of Northern Ireland remained a contested issue. Within Northern Ireland, a mainly 
Protestant majority wished to remain part of the U.K. while a large mainly Catholic minority campaigned for unity with the Republic. The Catholic minority in Northern Ireland were also, on the whole, less prosperous than the Protestant majority even though for much of this period, Northern Ireland had higher income per capita than the republic of Ireland. From 1922 to 1973, Northern Ireland was self-governed via its own Parliament (Stormont) from 1922 to 1973.

The period often referred as the "The Troubles" spans the period from 1969 until the mid 1990s and encompasses the main period of conflict studied. A series of events triggered a campaign of violence involving paramilitaries from both sides - frequently referred to as Loyalists and Republicans, the former wishing to remaining part of the U.K. and the latter seeking Irish unity. The main paramilitary organisation on the Republican side was the Irish Republican Army (IRA). From 1969, British troops were deployed on the streets of NI and from 1973, the British government suspended home rule and ran the province directly from Westminster. There were approximately 3500 deaths over this period of which around 1860 were "civilians", around 390 were members of "republican" paramilitary groups, and around 150 were deaths of members of "loyalist" paramilitary groups.

The Peace Process was initiated on December 15, 1993 when the Prime Ministers of Ireland and the UK sign the "Downing Street Declaration". This affirmed the right of the people of Northern Ireland to self-determination, and that the province would be transferred to the Republic of Ireland from the United Kingdom if and only if a majority of its population was in favour of such a move. It also pledged the governments to seek a peaceful constitutional settlement and promised that parties linked with paramilitaries (such as Sinn Féin) could take part in the talks, so long as they abandoned violence. In response to this, on August 31, 1994, the Irish Republican Army declared a cease-fire.

The next event of major significance was in 1998 when the Belfast Agreement (normally referred to as the Good Friday Agreement) was signed. Its key provisions include affirmation of the principle that any change to the constitutional status of Northern Ireland could only follow a majority vote of its citizens, commitment by all parties to use "exclusively peaceful and democratic means" and establishment of a Northern Ireland Assembly with devolved legislative powers. On June 25,1998, elections to a new Northern Ireland Assembly took place. Following this, on August 15, 1998, the Omagh bombing by a breakaway faction of the IRA killed 29 people leading 
to concerns about the stability of the peace process. Moreover, between October 14, 2002 - May 7, 2007, the Northern Ireland Assembly was suspended following allegations of spying.

The peace process took a further leap forward in July 28, 2005 when the IRA made a public statement ordering an end to the armed campaign and instructing its members to dump arms and to pursue purely political means. Following this, on May 8, 2007, home rule was restored following fresh elections to the Northern Ireland Assembly.

One key feature of the peace process is the degree of uncertainty about how successful it was going to be. Between the landmark events that we have noted, there was a huge amount of discussion concerning whether the process would ultimately yield a peaceful outcome. One of the major uncertainties surrounded the issue of decommissioning weapons and what process of verification would be needed to create mutual trust.

To get a feel for how successful the peace process was in reducing killing, we produce a graph (Figure 1) on aggregate killings in Northern Ireland over our data period. ${ }^{1}$ The rapid fall in violence after the IRA cease fire in 1994q4 is clearly apparent as is the tick up after the Omagh bombing in 1998q3. By and large, the effect of the peace process in the aggregate is clear.

\section{Related Literature}

This paper is related to a large existing literature that looks at how amenities are capitalized into house prices. One important strand of this literature surveyed by Boyle and Kiel (2001) looks at the impact of environmental externalities on house prices. Their survey suggests rather mixed success in being able to explain differences in house prices by measures of air quality, water quality, land usage and pollutants.

There is also a long tradition of looking at the relationship between school quality and house prices which is particularly relevant in the U.S. given the extensive use of local property taxes to fund education. Kain and Quigley (1975) is a classic reference in this field. More recently, Black (1999) is an excellent example of how empirical studies of these issues can exploit differences across jurisdictions over time. Using the fact that she can locate people within a district who are close to boundaries, she finds that a $5 \%$ improvement in test scores leads to a $2.5 \%$ increase in house prices. Her study

\footnotetext{
${ }^{1}$ Details on this variable are provided in section four.
} 
deals persuasively with the possibility of reverse causation issues that often plague such studies. Quigley and Rosenthal (2005) provides an overview of the link between house prices and land-use planning. While there is some support for the importance of such influences on house prices, they point out some of the serious empirical issues that beset the literature and interpretation of effects.

Our study relates to studies of the impact of crime on housing prices. One recent example is the study of the impact of sex offenders by Linden and Rockoff (2008). They use the exact location and moving in date of sex offenders to estimate their impact on housing prices in the immediate proximity of the offender's house. Their results suggest a price decrease of 4 percent of housing in a 0.1 mile radius around the sex offender's home after he/she moved in. Beyond the 0.1 mile radius, however, house prices seem to be unaffected. Another recent example is Gibbons (2004) who uses a cross-section of London property crime data to estimate the impact of these crimes on housing prices. He finds that an increase of one standard deviation in property damage goes hand in hand with a 10 percent drop in property prices.

There are a number of existing studies that look at the link between violence and economic outcomes. In the first study of its kind, Abadie and Gardeazabal (2003) use a synthetically constructed region which has the same structural features as the Basque Country to identify the effect of conflict related deaths on the economy. After the outbreak of terrorism in the late 1960's, per capita GDP in the Basque Country declined about 10 percentage points relative to a synthetic control region without terrorism. They also find that stocks of firms with a significant part of their business in the Basque Country showed a positive relative performance when truce became credible, and a negative relative performance at the end of the ceasefire.

Frey, Luechinger and Stutzer (2008) study life satisfaction scores using the Euro barometer and compare NI with the rest of the UK and the Republic of Ireland finding that that terrorist incidents are negatively correlated with happiness. Willard, Guinnane and Rosen (1996) use an event study to look at the impact of victories on the Union's Greenback's value in gold. Zussman, Zussman and Orregaard Nielsen (2008) looks for a structural break in stock price returns in Israel and the Palestinian territories around key events affecting the Israeli-Palestinian conflict. They find a significant effect of key events on asset prices. In an ingenious contribution Guidolin and La 
Ferrara (2007) look at the effect of war on the stock market value of firms using data from diamond mining firms in Angola. They use an event study methodology around the 2002 death of the rebel movement leader to identify the effect of conflict end. Collins and Margo (2007) studies the impact of riots on property prices in a cross-section of 104 US cities in the 1960s and 70s. They argue that if a riot causes a sustained decline in perceived amenities, then this should show up in the relative decline of property values in the affected city. In order to tackle the endogeneity and unobserved heterogeneity problems they instrument for riots with rainfall.

Even though the Northern Ireland conflict is not always classified as a civil war on standard definitions, this paper is also a contribution to burgeoning economics literature on the causes and consequences of conflict - see Elbadawi and Sambanis (2002) for a review. Most of that literature is focused on the causes rather than the consequences of violent conflict. However, one important issue is how far the cessation of conflict does lead to economic gains which have a self-reinforcing impact on peace. To the extent that capital losses on assets follow the onset of war, we should expect the mechanism that we study here to have an impact on the sustainability of peace in the long run. Given that housing is a major asset that is fixed in place, it is a good place to start in exploring the possibility of a peace dividend.

We use Markov chain dynamics in this paper. This is also the strategy employed by Blomberg and Hess (2002) which analyzes the connection between economic well-being and conflicts. Like us, their analysis makes extensive use of persistence estimates of conflict, peace, recession and boom. However, their data does not allow these states to be defined endogenously as we do here. We show here that the measurement of regional heterogeneity is likely to be affected by the way conflict is defined.

\section{Data and linear results}

As mentioned above, the data come from quarterly observations on eleven regions of Northern Ireland since October 1984. The housing price index that we used comes from a survey of more than a thousand open market housing transactions every quarter. Our data-set uses the average overall housing price in a region and does not differentiate by housing type. It is not surprising in the broader economic context of this period, which includes a housing boom in the U.K. and the Republic of Ireland, that house prices 
have been increasing. Figure 2 shows this using the natural logarithm of house prices in each of the eleven regions (the dashed line shows the average across regions). Average nominal house price growth is $9 \%$ per year. All eleven time series are characterized by a boom in house prices starting in the second half of the 1990s, accelerating from 2000 onwards and again falling after 2007. However, most of the variation in Figure 2 is not helpful in identifying the peace dividend because growth runs parallel across all regions. It can therefore not be disentangled whether it is caused by the end of the conflict or other common factors. ${ }^{2}$

We measure violence by the number of killings in a region - it is the clearest and most objectively measurable indicator. We use the Conflict Archive on the Internet (CAIN) website which records the details of every death arising from the present conflict in Ireland from newspaper cuttings, funerals, court records, cemeteries and books and pamphlets. The record gives the date of death of every victim, the name, his or her age, their 'status' in relation to the conflict, which organization killed them, and a brief description of the circumstances of their death. In addition, the data set provides an almost exact address which allows for a matching to the house price data. In this section we provide a brief discussion of the data (for details see the appendix) and a first, naive estimate for the link between conflict and housing prices. The coded data includes all deaths in Northern Ireland that are regarded conflict-related by our source. The maps shown in Figure 3 give a sense of how violence varied across time in the regions that we study. This makes clear our point that there is a large measure of heterogeneity in the incidence of violence across Northern Ireland. In particular, the maps show that while violence dropped radically in some regions others are constantly peaceful on the measure that we use. However, it is likely that these regions will have been affected by other manifestations of the Troubles.

We begin our analysis by estimating the relationship between house prices and killings using the following semi-log model:

$$
\ln \left(H_{r t}\right)=\alpha_{r}+\alpha_{t}+\beta y_{r t}+\varepsilon_{r t}
$$

where $\ln \left(H_{r t}\right)$ is the natural log of our house price index for region $r$ at date $t, y_{r t}$ is the number of killings in region $r$ at date $t, \alpha_{r}$ are region dummies, $\alpha_{t}$ are quarterly time dummies. We can interpret $\beta$ (which we expect to

\footnotetext{
${ }^{2}$ What our regression analysis will use in a sense is the deviation from the mean houseprice (dashed line) within the regions.
} 
be negative) as an average treatment effect of a "death" on house prices. The key "identifying" assumption is that there is no feedback from economic factors onto the pattern of violence conditional on $\left(\alpha_{r}, \alpha_{t}\right)$. We will also include $y_{r t-1}$ rather than $y_{r t}$.

An improvement in economic conditions following on from the peace process could be the conduit for the effect of violence on house prices. To some extent, we will be able to see whether or not this is the case by including the unemployment rate, which fell sharply over this period, as a time varying regressor. We will also include region specific time trends for similar reasons.

Some indicative results are in Table 1 . Column (1) gives the raw correlation between quarterly killings and house prices in the following quarter excluding any region or time effects. This correlation is negative and significant. Column (2) includes region effects and the correlation remains negative, although increases in size. Quarterly dummies are added in column (3). As expected from figure 2, taking out macro-effects in this way leads to a much smaller, although still negative and significant, correlation. Column (4) shows that this correlation is robust to the introduction of regionspecific time trends. Column (5) lags killings by half a year and the negative correlation result holds up (becoming a little larger in size). The linear estimate seems even robust to controlling for unemployment which takes on the expected sign.

These linear OLS results are interesting but there are some conceptual issues in interpreting them as a measure of the peace dividend. First, killings are treated symmetrically no matter where they occur, but this is not entirely satisfactory given that the amount of violence varies so much across regions. We might expect an area like Belfast where killings are much more prevalent to respond more to the peace process. We would therefore expect an heterogeneous and non-linear treatment effect. Second, the estimates conflate two things: the value to potential homeowners of reduced killing (the "true" peace dividend) and changes in expectations about how killings map into an assessment of whether the peace process will be sustained. While we cannot measure the latter directly, we can use a simple economic model to calibrate this effect and then decompose our estimate into an expectations effect and a dividend based on this estimate. To do this, we will need to develop a statistical model of the peace process and the way that killings changed the probability of sustained peace. We now develop such a model to see what it predicts for the relationship between killings and house prices. 


\section{A Model of House Prices and Violence}

In this section, we develop a theoretical model linking house prices and violence. We then introduce a stochastic process for the peace process. Finally, we show how the parameters of this model can be estimated using methods that have been developed to model business cycle dynamics.

\subsection{A Model of House Prices}

We assume a standard dividend-discount model of house prices where houses are infinitely lived and potential home owners have rational expectations. Assume also that the consumption value of the house (the dividend) in region $r$ at date $t$ can be decomposed into a "standard" part based on amenities such as location and a part which depends on the level of violence. We write this as:

$$
u_{r t}=h_{r}+\alpha y_{r t}
$$

where $h_{r}$ is the standard consumption value of housing based on fixed locational factors, $y_{r t}$ is violence in period $t$ and $-\alpha>0$ is the peace dividend that represents how the absence of violence is being valued by residents. We treat the component $h_{r}$ as fixed by region for simplicity of exposition. In the empirical analysis we allow there to be a common time effect and/or a region specific time trend.

We interpret $\alpha$, in line with the literature on amenities and house prices, as representing the local public bad associated with killings in a neighborhood. In our context, this is more plausible than thinking about the personal risk of being a victim. In part, therefore, $\alpha$ should pick up the general change in the environment and defensive measures taken to protect citizens which lowered the quality of life for residents during the Troubles.

The present value of the dividend stream determines house prices. It is now given by:

$$
E\left[\sum_{i=0}^{\infty}\left(\beta^{i} u_{r t+i}\right) \mid \psi_{r t}, \theta_{r}\right]=\frac{h_{r}}{1-\beta}+\alpha E\left[\sum_{i=0}^{\infty}\left(\beta^{i} y_{r t+i}\right) \mid \psi_{r t}, \theta_{r}\right]
$$

where $\psi_{r t}$ denotes the history of violence up to date $r$ at time $t, \theta_{r}$ are the parameters of the process generating violence in region $r$ and $\beta$ denotes the discount rate which is assumed to be common across time and regions.

The impact of current violence on house prices will now depend on how it changes the second term in (2). If more killings lead potential home owners 
to update their view of future violence, then we expect a negative relationship between (2) and violence in region $r$ at date $t$. But this depends critically on the properties of the assumed process for $y_{r t}$ which is affected by the peace process - an unobserved state about which homeowners are learning.

\subsection{The Peace Process}

We model the peace process as an independent Markov chain. Let $s_{r t} \in$ $\{0,1\}$ which determines whether region $r$ is in peace or in conflict at date $t$ where 0 denotes peace. This state is not observed directly - we can only measure the amount of violence $y_{r t}$. Both are linked through the following switching model:

$$
y_{r t}=\mu_{r 0}\left(1-s_{r t}\right)+\mu_{r 1} s_{r t}+\varepsilon_{r t} \text { with } \varepsilon_{r t} \sim N\left(0, \sigma_{r s_{r t}}^{2}\right) .
$$

Thus, $\mu_{r 0}$ is the mean number of killings in the peaceful state and $\mu_{r 1}$ is the number of killings in conflict. This allows for the possibility that $\mu_{r 0}>0$. This is consistent with the standard approach taken in the literature on civil wars where there is a threshold level of killings which needs to be passed before a region or country is deemed to be in a state of civil war.

We allow the mean (and variance) of violence in each region to be a function of this state. We posit four transition probabilities between peace and conflict denoted by:

$$
\begin{aligned}
& p\left(s_{r t}=1 \mid s_{r t-1}=1\right)=p_{r} \\
& p\left(s_{r t}=0 \mid s_{r t-1}=1\right)=1-p_{r} \\
& p\left(s_{r t}=0 \mid s_{r t-1}=0\right)=q_{r} \\
& p\left(s_{r t}=1 \mid s_{r t-1}=0\right)=1-q_{r}
\end{aligned}
$$

The parameters $\theta_{r}$ in (2) are now the means and variances of violence in the two states as well as the transition probabilities across these states.

The state in region $r$ at date $t$, follows the process:

$$
s_{r t}=1-q_{r}+\lambda s_{r t-1}+v_{r t} \text { where } \lambda_{r}=q_{r}+p_{r}-1
$$

where $v_{r t}$ is an error term with a state-contingent distribution of

$$
v_{r t} \mid\left(s_{r t-1}=1\right)=\left\{\begin{array}{ccc}
1-p_{r} & \text { with probability } & p_{r} \\
-p_{r} & \text { with probability } & 1-p_{r}
\end{array}\right.
$$


and

$$
v_{r t} \mid\left(s_{r t-1}=0\right)=\left\{\begin{array}{clc}
-\left(1-q_{r}\right) & \text { with probability } & q_{r} \\
q_{r} & \text { with probability } & 1-q_{r} .
\end{array}\right.
$$

The forecast for the next period is dependent on the beliefs on the state $s_{r t}$ now which are based on the whole history $\psi_{r t}$, available up to period $t$ which includes all past killings in the region. Formally

$$
\begin{aligned}
E\left(y_{r t+1} \mid \psi_{r t}\right)= & p_{r} \mu_{r 1} P\left(s_{r t}=1 \mid \psi_{r t}, \theta_{r}\right)+\left(1-q_{r}\right) \mu_{r 1} P\left(s_{r t}=0 \mid \psi_{r t}, \theta_{r}\right) \\
& +q_{r} \mu_{r 0} P\left(s_{r t}=0 \mid \psi_{r t}, \theta_{r}\right)+\left(1-p_{r}\right) \mu_{r 0} P\left(s_{r t}=1 \mid \psi_{r t}, \theta_{r}\right)
\end{aligned}
$$

with $P\left(s_{r t}=1 \mid \psi_{r t}, \theta_{r}\right)=1-P\left(s_{r t}=0 \mid \psi_{r t}, \theta_{r}\right)$.

This allows us to use standard techniques to construct the projection of past violence onto the expectation of future violence for which we have:

$$
\begin{aligned}
E\left(y_{r t+1} \mid \psi_{r t}, \theta_{r}\right)= & \mu_{r 1}\left[\pi_{r}+\lambda_{r}\left(P\left(s_{r t}=1 \mid \psi_{r t}, \theta_{r}\right)-\pi_{r}\right)\right] \\
& +\mu_{r 0}\left[1-\pi_{r}+\lambda_{r}\left(P\left(s_{r t}=0 \mid \psi_{r t}, \theta_{r}\right)-1+\pi_{r}\right)\right]
\end{aligned}
$$

where $\pi_{r} \equiv \frac{1-q_{r}}{2-p_{r}-q_{r}}$.

This model gives us as a fairly straightforward expression for the second term in (2) which can be written as:

$$
\begin{aligned}
E\left[\sum_{i=0}^{\infty}\left(\beta^{i} y_{r t+i}\right) \mid \psi_{r t}, \theta_{r}\right]= & \frac{\mu_{r 1} \pi_{r}+\mu_{r 0}\left(1-\pi_{r}\right)}{1-\beta} \\
& +\left(\mu_{r 1}-\mu_{r 0}\right) \frac{P\left(s_{r t}=1 \mid \psi_{r t}, \theta_{r}\right)-\pi_{r}}{1-\lambda_{r} \beta} .
\end{aligned}
$$

This has an intuitive interpretation. The first expression is the mean discounted present of "permanent" violence which is most easily seen when either peace is an absorbing state $\left(\pi_{r}=0\right)$ or conflict is an absorbing state $\left(\pi_{r}=1\right)$.

The second expression varies over time in response to how information derived from the history of violence over the relevant time period is updated. The term shows that the impact of $P\left(s_{r t}=1 \mid \psi_{r t}, \theta_{r}\right)$ on expected violence is affected by the general persistence of the violence process, $\lambda_{r}$. More specifically, a $\lambda_{r}$ close to one means that both peace and conflict are highly persistent and the probability of being in conflict has a large impact on the present value of violence. Provided that we can produce estimates of the key underlying parameters and the probability of conflict, we will be able to construct an empirical counterpart for expression (3). We will call this estimate $\widehat{P D V}$ rt and we will use it as a regressor to explain house prices in line with equation (2). 


\subsection{Implementing the Model}

The key parameters of the model described in the previous section are $\theta_{r} \equiv$ $\left(\mu_{r 1}, \mu_{r 0}, \sigma_{r 1}^{2}, \sigma_{r 0}^{2}, p_{r}, q_{r}\right)$. Once these parameters are known it is possible to calculate the probability of conflict $P\left(s_{r t}=1 \mid \psi_{r t}, \theta_{r}\right)$ by using the panel data on violence $y_{r t}$ in a filter provided by Hamilton (1989). Given the central role of the probability of conflict we discuss the filter before turning towards the estimation of $\theta_{r}$.

A good starting point for the calculation of the probability of being in conflict, $P\left(s_{r t}=1 \mid \psi_{r t}, \theta_{r}\right)$, is Bayesian updating in period $t$. In period $t$, the extrapolation of last period $P\left(s_{t}=1 \mid \psi_{r t-1}, \theta_{r}\right)$ is updated with killings in $t$ according to the standard formula:

$$
P\left(s_{r t}=1 \mid \psi_{r t}, \theta_{r}\right)=\frac{f\left(y_{r t} \mid s_{r t}=1, \psi_{r t-1}, \theta\right) P\left(s_{r t}=1 \mid \psi_{r t-1}, \theta_{r}\right)}{\sum_{j=0}^{1} f\left(y_{r t} \mid s_{r t}=j, \psi_{r t-1}, \theta_{r}\right) P\left(s_{r t}=j \mid \psi_{r t-1}, \theta_{r}\right)} .
$$

The immediate insight from this formula is that the probability can only be calculated with an estimate of $\theta_{r}$ because the conditional densities are given by

$$
f\left(y_{r t} \mid s_{r t}=j, \psi_{r t-1}, \theta\right)=\frac{1}{\sqrt{2 \pi \sigma_{r j}^{2}}} \exp \left(-\frac{\left(y_{r t}-\mu_{r j}\right)^{2}}{2 \sigma_{r j}^{2}}\right)
$$

and therefore depend on parameters in $\theta_{r}$.

The probability $P\left(s_{r t}=1 \mid \psi_{r t}, \theta_{r}\right)$ can be calculated if the past estimate $P\left(s_{r t-1}=1 \mid \psi_{r t-1}, \theta_{r}\right)$ is known. ${ }^{3}$ This reliance of $P\left(s_{r t}=1 \mid \psi_{r t}, \theta_{r}\right)$ on $P\left(s_{r t-1}=1 \mid \psi_{r t-1}, \theta_{r}\right)$ implies that previous probabilities of conflict have to be calculated first. The filter therefore takes a starting value $P\left(s_{r 0}=1 \mid \psi_{r 0}, \theta_{r}\right)$

${ }^{3}$ To see that this dependency of $P\left(s_{t}=1 \mid \psi_{t-1}, \theta\right)$ on $P\left(s_{t-1} \mid \psi_{t-1}, \theta\right)$ note that

$$
P\left(s_{t}=1 \mid \psi_{t-1}, \theta\right)=\sum_{j=0}^{1} P\left(s_{t}=1, s_{t-1}=j \mid \psi_{t-1}, \theta\right) .
$$

and

$$
P\left(s_{t}=1, s_{t-1}=j \mid \psi_{t-1}, \theta\right)=P\left(s_{t}=1 \mid s_{t-1}=j\right) P\left(s_{t-1}=j \mid \psi_{t-1}, \theta\right)
$$

where $P\left(s_{t}=1 \mid s_{t-1}=j\right)$ is nothing else than the estimated $p$ and $1-q$ contained in $\theta$. Hence, one needs $P\left(s_{t-1}=1 \mid \psi_{t-1}, \theta\right)$ to calculate $P\left(s_{t}=1 \mid \psi_{t}, \theta\right)$. 
and calculates

$$
P\left(s_{r 1}=1 \mid \psi_{r 1}, \theta_{r}\right), P\left(s_{r 2}=1 \mid \psi_{r 2}, \theta_{r}\right) \ldots P\left(s_{r T}=1 \mid \psi_{r T}, \theta_{r}\right)
$$

by iteratively updating the probability of conflict with the quarterly violence data $y_{r t}$. To some degree this is what a potential house-purchaser in region $r$ would have done, too.

However, this simple filter relies on the availability of the vector $\theta_{r}$. The problem is that $\theta_{r}$ cannot be calculated without knowing the states $s_{r 1}, s_{r 2} \ldots s_{r T}$ which are unobserved. Hence, the estimation method needs to determine when regime shifts occurred and at the same time estimate the parameters of the model. One way of estimating the parameters of the violence process is the Expectation Maximization (EM) Algorithm described in Hamilton (1990) which generates an estimate of $\theta_{r}$ by iteration.

In each iteration the algorithm makes use of the "smoothed" probability of conflict which is based on the entire violence data for a region ${ }^{4}$

$$
P\left(s_{r t}=1 \mid y_{r T}, y_{r T-1}, \ldots, y_{r 1}, \theta_{r}\right) .
$$

These probabilities are then used to generate a distribution over the $T^{2}$ possible combinations of states $s_{r 1}, s_{r 2} \ldots s_{r T}$ which is used to re-weight the violence data $y_{t}$. This weighted violence data can then be used to generate new estimates of the vector $\theta_{t}$ as if the underlying states were known. The next iteration then starts by re-calculating the smoothed probabilities under the new vector $\theta_{r}$. The process is repeated until a fixed point for $\theta_{r}$ is found. Hamilton (1990) shows that this fixed point is also the maximum likelihood estimate. ${ }^{5}$

Table 2 presents the results of running the EM Algorithm for each of the 11 regions separately. The four columns show our estimates of $\mu_{r 1}, \mu_{r 0}, p_{r}$ and $q_{r}$. Quite clearly, Belfast is the most violent region with almost eight killings per quarter in conflict and over one in peacetime. Other regions like Londonderry/Strabane or Mid/South Down are less violent on average but also display long persistence in their conflict (high values of $p_{r}$ ). As noted earlier, this persistence is an important feature of a conflict because it increase the leverage that present violence has on expectations.

\footnotetext{
${ }^{4}$ See Hamilton (1990) or Kim and Nelson (1998) for an explanation of smoothing and the connection to the EM Algorithm.

${ }^{5}$ The implementation of this procedure was simplified significantly by the provision of GAUSS programs by James Hamilton under http://weber.ucsd.edu/ jhamilto/software.ht.
} 
This point becomes clear when one compares, for example, the region Londonderry/Strabane with East Antrim. East Antrim features similar estimates of $\mu_{r 1}$ and $\mu_{r 0}$ as Londonderry/Strabane but an estimate of $p_{r}$ close to zero. That means that outbursts of violence will have relatively little impact on expectations of future violence in East Antrim as conflict is not persistent. ${ }^{6}$

Figures 4, 5 and 6 show the results of this methodology by comparing the fitted values of violence

$$
\hat{y}_{r t}=\mu_{r 0}+\left(\mu_{r 1}-\mu_{r 0}\right) P\left(s_{r t}=1 \mid \psi_{r t}, \theta_{r}\right)
$$

with the raw violence data $y_{r t}$ in three different regions. An immediate observation is that only a relatively narrow band of movements in violence triggers a change in $P\left(s_{r t}=1 \mid \psi_{r t}, \theta_{r}\right)$ and, hence, in the fitted value $\hat{y}_{r t}$. This is because the estimated likelihood of conflict is mostly either close to one or close to zero. Nonetheless, we regard this as a reasonable way of weighting the data since a change between ten and twenty killings, for example, carries less information about whether, say, Belfast is in conflict than a change from zero to ten killings.

Our estimation of the peace dividend uses the weighted series $\hat{y}_{r t}$. The weights are determined by the region-specific transition probabilities $p_{r}$ and $q_{r}$. How important the weighting is can be seen by comparing the graphs of the two violent regions with the graph for Lisburn. While Lisburn had some violent incidents, violence rarely persisted for more than one quarter. A look at table 2 confirms that our estimate of $p_{r}$ is 0.288 for Lisburn which is low compared to the numbers of over 0.9 in both Belfast and Londonderry/Strabane. Thus, we would expect a change from peace to conflict to have very different implications for expectations and, hence, house prices in the three regions. If we were to use $\hat{y}_{r t}$ directly this fact would be ignored.

\section{Results}

This section presents the core results as well as a number of variants and robustness checks.

\footnotetext{
${ }^{6}$ The fact that $\lambda_{r}<0$ in this case does not affect the result. In fact, our regression results would remain unchanged if the three violence time series for which this is the case were replaced with zeros.
} 


\subsection{Core Results}

The core results are in Table 3. They come from running regressions of the form:

$$
\ln \left(H_{r t}\right)=\alpha_{r}+\alpha_{t}+\beta \widehat{P D V_{r t-1}}+\varepsilon_{r t}
$$

where, as above, $\alpha_{r}$ are region dummies, $\alpha_{t}$ are quarterly time dummies. The variable $\widehat{P D V}_{r t}$ is our computed measure of the expected discounted number of future killings from (2) as computed in the previous section. Given that $\widehat{P D V}_{r t}$ is highly non-linear, we bootstrap the standard errors. We will assess the robustness of the approach to timing and the assumed discount factor. As our baseline case we choose a $5 \%$ discount rate.

Column (1) of Table 3 shows that there is a significant negative correlation between our (lagged) measure of the discounted value of violence and house prices. Below, we will discuss the size of this effect in economic terms. Column (2) shows that this correlation remains when the present value is calculated with a discount rate of $1 \%$. Although the size of the coefficient changes quite dramatically, it turns that it is similar in magnitude from an economic point of view. In column (3), we test robustness of our core result to lagging our present discounted value measure by half a year. The result is robust. Column (4) introduces the unemployment rate as an additional regressor. The coefficient on the present discounted value measure of killings is identical. Finally, column (5) introduces region specific time trends. Although the size of the coefficient is a little smaller the core correlation that we would expect if there is a genuine peace dividend is present in the data.

Taken together these results provide convincing evidence of a Northern Ireland peace dividend. We now assess the robustness of this finding.

\subsection{Heterogeneity}

The measure that we are using to estimate the impact of killing on house prices is naturally heterogenous with respect to the region and timing of killings. However, it is still interesting to see whether there is any further heterogeneity by interacting this variable with other characteristics of each region which arguably could have a bearing on the likelihood and impact of conflict.

We choose three such measures: (i) the population size, (ii) the level of pre-sample violence in each region and (iii) measures of Protestant-Catholic 
polarization. In each case, we interact the variable $\widehat{P D V}_{r t}$ in equation (4) with the variable in question. The results are presented in Table 4.

In column (1), we use present value per capita as a regressor. The core result is robust to this. It is re-assuring that our results are not driven by higher population numbers in more violent areas. Column (2) contrasts the per capita measure with the original present value measure. It turns out that the per capita measure is much weaker than the present values itself. This lends some support to the view that killings are a regional public bad. Individuals care about the level of violence in the region when they buy a house not their own probability of being killed.

Column (3) has the interaction with pre-sample violence, column (4) with the share of Catholics and column (5) with our measure of religious polarization constructed from this share. ${ }^{7}$ Looking across the table, it is clear that none of these interactions is significantly different from zero suggesting that our heterogeneous measure in $\widehat{P D V}_{r t}$ is already doing a decent job at picking up the way that a given death has an impact on house prices. ${ }^{8}$

\subsection{Alternative Specifications}

The Probability of Conflict as a Regressor We have supposed that it is killing which reflects the amenity cost of living in a neighborhood. However, another interpretation of the results is that it is the probability of unobserved latent state - peace or conflict - that really matters. After all, there are many aspects of violence beyond killings that made life during the Troubles unpleasant and these are likely correlated with killings.

Suppose instead, therefore, that house prices are not affected by killings but by the underlying state $s_{t}$. Hence the utility flow from a house is now:

$$
u_{r t}=h_{r}+\alpha^{\prime} s_{r t} \text {. }
$$

Here, the amenity is peace itself. This slightly modified utility function gives

\footnotetext{
${ }^{7}$ See the appendix for more details on the polarization measure.

${ }^{8}$ In the Appendix we show results form re-estimating the semi-log model with interaction terms. Interactions with pre-sample violence and the share of Catholics living in a region are significant. However, in view of the results from Table 4, it is clear that these interaction terms are really only proxying for underlying differences across regions which our economic model is capturing.
} 
rise to the following present value of housing:

$$
E\left[\sum_{i=0}^{\infty}\left(\beta^{i} P\left(s_{r t}=1 \mid \psi_{r t}, \theta_{r}\right)\right)\right]=\frac{1-q_{r}+h_{r}}{1-\beta}+\frac{P\left(s_{r t}=1 \mid \psi_{r t}, \theta_{r}\right)}{1-\lambda_{r} \beta} .
$$

Our basic method can be adapted to assess the robustness of our findings to this alternative view.

In column (1) of Table 5. we include the estimated value of $\frac{P\left(s_{r t}=1 \mid \psi_{r t}, \theta_{r}\right)}{1-\lambda_{r} \beta}$ in place of $\widehat{P D V}{ }_{r t}$. A similar qualitative story emerges. In particular, the result seems very robust to controlling for unemployment and regions specific time trends (column (2)). The magnitude of the effect, however, is relatively low. This is perhaps not too surprising given that $\widehat{P D V}_{r t}$ is really an interaction term between the probability and the region-specific difference $\left(\mu_{r 1}-\mu_{r 0}\right)$. Hence, if we focus on the conflict probability we are neglecting the regional heterogeneity in terms of severity of violence, i.e. the intensity of violence effect.

Neighborhood Spillovers Our core results assume that the impact of violence is confined to the geographic area for which we measure house prices. However, it may be that home owners care about the level of violence in other regions when choosing where to live. This could either be because of a direct spillover or because home owners are choosing ex ante where to live creating general equilibrium price changes.

To consider this possibility, we look for spillover effects from the most violent regions: Belfast, Craigavon/Armagh, Londonderry/Strabane, Mid Ulster and Mid/South Down onto house prices in adjacent regions. Thus, we create a dummy variable denoting whether a region has a boundary with one of these regions and interact that with the $\widehat{P D V}$ in the adjacent region. These interaction terms are shown in column (3) and give us an interesting finding. First, we find a core "own correlation" which is negative and significant and of similar magnitude to the core results. Among the interaction terms all results bar Belfast are suggestive of a negative spillover of violence across regions. However, only one of these coefficients is significant. ${ }^{9}$ The correlation of house prices in adjacent neighborhoods with Belfast is positive. This is consistent with a flight away from living in Belfast to adjacent neighborhoods in response to the violence. Although we do not have evidence on

\footnotetext{
${ }^{9}$ The Mid/South Down region had a relatively high share of killings of British Army soldiers - it is not unreasonable that the effect of these killings is less local.
} 
migration directly, this explanation is consistent with broad changes in population captured by population statistics provided by the Northern Ireland Statistics and Research Agency (NISRA). According to their data, population in Belfast declined from 316,358 inhabitants in 1981 to 267,374 in $2006 .^{10}$ The view that this reflects at least partly local migration is supported by the fact that population increased in all other twenty-four local government districts throughout the same period.

A Single Index Model Our independent Markov chain model is flexible in that it allows each region of Belfast to be in a state of peace of conflict independently. Hence, home owners are deemed to make a local assessment of the peace process and what it means for them in the locality. However, another plausible view is that the core assessment on peace is a macro-effect effect based on all violence in Northern Ireland. ${ }^{11}$ On this view, we should model the probability of peace as a single index.

We implement this idea as follows. First, we add all the regional quarterly killings to create an aggregate Northern Irish time series of killings. This time series is then fed into the EM Algorithm to produce an estimate of the probability of conflict for Northern Ireland as a whole which is now $P\left(s_{t}=1 \mid \psi_{t}, \theta_{t}\right)$. Figure 7 shows the EM estimate of total violence $\hat{y}_{t}$ together with the total Northern Irish violence from figure 1. As can be seen in the graph, the estimated probability of conflict, and with it the violence estimate, declines in the first quarter of 1995 but shoots back up around the time of the Omagh bombing.

In a second step, we test the extent to which this probability of violence for Northern Ireland as a whole can explain regional violence variation. We do this simply by running eleven OLS regressions:

$$
y_{r t}=\gamma_{r}+\tau_{r} P\left(s_{t}=1 \mid \psi_{t}, \theta_{t}\right)+\varepsilon_{r t} .
$$

This creates an estimate of the average level of violence $\left(\gamma_{r}\right)$ and the impact of the Northern Irish conflict $\left(\tau_{r}\right)$ for each region. Depending on the magnitudes of regional violence and the correlation with $P\left(s_{t}=1 \mid \psi_{t}, \theta_{t}\right)$, this gives an new estimate of the mean levels of violence during peace and

\footnotetext{
${ }^{10}$ NISRA population data is available online under http://www.nisra.gov.uk/. The population statistics give population densities and area.

${ }^{11}$ We are grateful to Daron Acemoglu for persuading us to look at this alternative interpretation.
} 
conflict. (The estimated region-specific intercept is the average death-count in peacetime while the estimated constant plus slope coefficient are the average death-count in conflict.) Note, however, that not all coefficients that we estimate this way are statistically significant. ${ }^{12}$ Most peaceful regions, for example, have no significant slope coefficient implying no impact of the estimated Northern Irish conflict on their regional violence levels. i.e. the series $P\left(s_{t}=1 \mid \psi_{t}, \theta_{t}\right)$ is simply not correlated with the $y_{r t}$ for such regions. As a final step we use the significant slopes and constants in each region to generate a panel of fitted killings. Figure 8 gives an idea of how these single index fitted values compare to the region-specific fitted values. The graph shows the the violence times series for Londonderry/Strabane plus both fitted values. As can be seen in the graph the single index time series translates the Northern Irish conflict into fitted values that do not correspond to violence movements in Londonderry/Strabane - in particular after 1995.

Columns (4) and (5) in Table 5 report the regression results when the single index fitted violence levels are introduced into our standard empirical model. Note that in this specification there is no difference between the present value and fitted killings because the persistence parameters $p$ and $q$ are now identical across regions. The core results of a negative correlation between house prices and this region specific measure of violence (based on a single index of a latent state) remains including when we add unemployment and region specific time trends as a regressor (column (5)).

Summary These additional results presented in Table 5 bear out the core finding of the paper that violence and house price prices are negatively correlated across the regions of Northern Ireland. Perhaps the main finding of substantive economic interest in this section is the evidence in favor of spillovers across regions.

\subsection{Economic Significance}

We now turn to the size of effect that is predicted by our empirical models. For this, we take the result in column (1) in Table 3 and use it to compute the $95 \%$ confidence interval of the percentage change in house prices associated with a unit change in present value. The boundaries of this interval are then

\footnotetext{
${ }^{12}$ We use levels of significance at ten percent. Alternative exclusion criterion would lead to similiar results.
} 
multiplied by the region-specific estimates of the present value of killings in conflict minus those in peace. The results are in Table 6 which also gives the present value estimates for completeness. In order to show the robustness of the quantitative results table 6 shows computations for the discount rates of $5 \%$ and $1 \%$.

A first observation is that the choice of discount rate is immaterial in economic terms. In looking at the estimates, we find that overall our model predicts that peace leads to an increase in house prices of between $1.7 \%$ and $3.1 \%$ all else equal. However, these effects are highly heterogeneous across regions. For Belfast where violence was greatest, the estimate for a change in house prices is between $8 \%$ and $14.5 \%$ using a $5 \%$ discount rate.

Another way to look at the economic significance of conflict is to compare its impact to that of unemployment. Column (4) of Table 3 gives us a rough idea about how unemployment might shape housing prices. The coefficient on the log of unemployment in column (4) indicates that the impact of a one standard deviation change $\left(\sigma_{\text {unemp }}=0.7303\right)$ is around $10.5 \%$, which is below the upper bound estimated for the impact of violence in Belfast and but considerably above the impact of violence in other regions.

It is interesting to compare these results with what would emerge from the average coefficient on killings which we estimate from the OLS. This is given in Table 7 . We make this effect heterogeneous by applying our estimates of the mean difference in violence from the Markov switching model. This model predicts a smaller effect of violence on house prices compared to the model based on a $\widehat{P D V} \widehat{P t}_{r t}$ calculation. The $95 \%$ confidence interval ranges from $0.8 \%$ to $1.9 \%$. But more striking is the way that the models handle heterogeneity in the impact of violence. For Belfast, the estimate is from $2.2 \%$ to $5.5 \%$ with the upper bound lying below the lower bound of the model based on $\widehat{P D V}_{r t}$. In general all the estimates of the OLS model in more violent regions are lower than their counterparts based on the non-linear model of violence.

It is important to stress in this context that the derived heterogeneity and magnitude are not a result of our basic methodology of estimating a different conflict process for each region. As can be seen in table 8, estimates of the above-mentioned single index model yields very similar results in both respects. This robustness is encouraging suggesting that choosing between this model of an aggregate peace process and the region-by-region model is of no great significance to the economic findings of the paper. 


\section{Concluding Comments}

This paper has looked at the effect of violence in Northern Ireland on house prices. The peace process of this region provides an interesting context in which to look at the peace dividend as measured by home owners willingness to pay for houses. The novelty of our study lies partly in the data - we have both spatial (within-region) and quarterly temporal variation in violence to exploit in measuring how much changes in violence has affected house prices. Our approach also compares findings from a standard OLS estimate with one derived from an empirical model which is more grounded in economic theory and a model of the underlying peace process.

Both approaches suggest that there is a negative relationship between house prices and killings in line with what we would expect. However, the economically motivated model yields rather different conclusions on the size of the peace dividend and its distribution across regions. This makes sense since we would expect the process that generates a mapping between house prices and violence to be non-linear when potential home owners are weighing up the pros and cons of purchasing a house. Also interesting is the evidence on spillover across areas suggesting that some kind of general equilibrium response to violence including migration across regions may be at work.

What we have estimated here is the non-macro component of the peace dividend. To the extent that there are common components that have lifted all regions of Northern Ireland, they are absorbed in the quarterly dummy variables. However, given other macro-effects including the rapid growth rate of the Republic of Ireland over this period, it is close to impossible to reliably estimate this effect. But it is perfectly possible that these effects are larger than those that we have estimated here.

Sustaining peace is always a challenge in places were there are long-lived political and social tensions. Part of sustaining peace is to convince those involved in supporting violence that there are manifest benefits to peace. This study shows that home owners' willingness to pay to live in regions were violence decreased in Northern Ireland created a tangible stake in the maintenance of peace. 


\section{References}

[1] Abadie, Alberto and Javier Gardeazabal (2003) The Economic Costs of Conflict: A Case Study of the Basque Country, American Economic Review, pp. 113-132.

[2] Black, Sandra, (1999), "Do Better Schools Matter? Parental Valuation of Elementary Education", Quarterly Journal of Economics, 114(2), pp. 577-599.

[3] Blomberg, S. Brock and Gregory D. Hess (2002) "The Temporal Links between Conflict and Economic Activity", Journal of Conflict Resolution, 46(1), pp. 74-90.

[4] Boyle, Melissa A. and Katherine A. Kiel, (2001), "A Survey of House Price Hedonic Studies of the Impact of Environmental Externalities," Journal of Real Estate Literature, 9(2), pp. 117-144.

[5] Collins, William J. and Robert A. Margo (2007) "The Economic Aftermath of the 1960s Riots in American Cities: Evidence from Property Values," Journal of Economic History, Vol. 67, No. 4, pp. 849-883.

[6] Dempster, A.P., N.M. Laird, and D.B. Rubin, (1977), "Maximum Likelihood Estimation from Incomplete Data via the EM Algorithm," Journal of the Royal Statistical Society B, 39, pp. 1-38.

[7] Elbadawi, Ibrahim and Nicholas Sambanis (2002). "How Much Civil War Will We See? Explaining the Prevalence of Civil War", Journal of Conflict Resolution 46, pp. 307-334.

[8] Frey, Bruno S. and Simon Luechinger and Alois Stutzer (2008), "The Life Satisfaction Approach to Valuing Public Goods: The Case of Terrorism,". Public Choice, forthcoming

[9] Gibbons, Steve (2004), "The Cost of Urban Property Crime", Economic Journal, 114, pp. F441-F463.

[10] Guidolin, Massimo and Eliana La Ferrara, (2007), "Diamonds Are Forever, Wars Are Not. Is Conflict Bad for Private Firms?", American Economic Review, 97(5), pp. 1978-93. 
[11] Hamilton, James D. (1990), "Analysis of Time Series Subject to Changes in Regime," Journal of Econometrics, 45, pp. 39-70.

[12] Hamilton, James D. (1989), "A new approach to the economic analysis of nonstationary time series and the business cycle," Econometrica, 57, pp. $357-384$.

[13] Kain, John F and John M. Quigley, (1975), Housing Markets and Racial Discrimination: A Micro-economic Analysis, New York, NY: NBER.

[14] Kim, Chang-Jin and Charles R. Nelson (1998), State-Space Models with Regime-Switching: Classical and Gibbs-Sampling Approaches with Applications, Boston MA, MIT Press.

[15] Linden, Leigh and Jonah E. Rockoff (2008), "Estimates of the Impact of Crime Risk on Property Values from Megan's Laws," American Economic Review, 98(3), pp. 1103-27.

[16] Montalvo, Jose G and Marta Reynal-Querol (2005), "Ethnic Polarization, Potential Conflict, and Civil Wars," American Economic Review, 95(3), pp. 796-816.

[17] Quigley, John M. and Larry Rosenthal, (2005), "The Effects of Land Use Regulation on the Price of Housing: What Do We Know? What Can We Learn?", Cityscape, 8(1), pp. 69-138.

[18] Sutton, Malcolm (1994), Bear in Mind these Dead ... An Index of Deaths from the Conflict in Ireland 1969-1993, Belfast: Beyond the Pale Publications.

[19] Willard, Kristen L, Timothy W. Guinnane and Harvey S. Rosen, (1996). "Turning points in the civil war: views from the Greenback Market," American Economic Review, 86, pp. 1001-18.

[20] Zussman, Asaf, and Noam Zussman, (2006). "Assassinations: evaluating the effectiveness of an Israeli counterterrorism policy using stock market data." Journal of Economic Perspectives, 20, pp. 193-206.

[21] Zussman, Asaf, Noam Zussman and Morten Orregaard Nielsen, (2008), "Asset Market Perspectives on the Israeli-Palestinian Conflict", Economica, 75, pp. 84-115. 


\section{Data Appendix}

Table 9 gives the summary statistics of the used and generated data. This sections will describe each of the variables in detail.

Killings: This variable relies on data from the Conflict Archive on the Internet (CAIN) website which presents updated work by Sutton (1994) who recorded the details of every killing arising from the present conflict in Ireland from newspaper cuttings, funerals, court records, cemetries and books and pamphlets. The book gives the date of the killing of every victim, the name, his or her age, their 'status' in relation to the conflict, which organization killed them, and a brief description of the circumstances of their death. In addition, the data set provides an almost exact address which allows us to match this to the house price data. For example:

\begin{tabular}{l|l|l} 
Example \\
$\begin{array}{l}25 \text { January } \\
1989\end{array}$ & David Dornan (26) Protestant & Killed by: \\
& Status: Civilian (Civ) & Ulster Freedom Fighters \\
\hline & Shot at his workplace, building site, Kingsmore Link Road, \\
& Lisburn, County Antrim. Assumed to have been a Catholic.
\end{tabular}

Housing Price: We use the house price index provided by the University of Ulster in cooperation with the Bank of Ireland and the Northern Ireland Housing Price Executive. The project surveys more than a thousand open market housing transactions every quarter. Data is provided for eleven regions starting from October 1984 until today (with the exception of a few quarters for which no reports could be found in the UK or Ireland). Our data-set uses the average overall housing price in a region and does not differentiate by housing type.

Population: The population and religion mix comes from the 1991 Census, Census Office for Northern Ireland. The data is by district council so that it has to be recoded to fit to house price regions. The fit is reasonable except for the district council Strabane which is split into two parts by two Housing Price Regions. As a simplification we treat the population (and unemployed) of Strabane as belonging half to the region Londonderry/Strabane and half to Enniskillen/Fermanagh/South Tyrone. 


\begin{tabular}{|c|c|}
\hline Housing Price Region & Census Districts \\
\hline Belfast & $\begin{array}{l}\text { Belfast } \\
\text { Castlereagh }\end{array}$ \\
\hline North Down & $\begin{array}{l}\text { Ards } \\
\text { North Down }\end{array}$ \\
\hline Lisburn & Lisburn \\
\hline East Antrim & $\begin{array}{l}\text { Carrickfergus } \\
\text { Larne } \\
\text { Newtonabbey }\end{array}$ \\
\hline Londonderry/Strabane & $\begin{array}{l}\text { Derry } \\
\frac{1}{2} \text { Strabane }\end{array}$ \\
\hline Antrim/Ballymena & $\begin{array}{l}\text { Antrim } \\
\text { Ballymena }\end{array}$ \\
\hline Coleraine/Limavady/N Coast & $\begin{array}{l}\text { Ballymoney } \\
\text { Coleraine } \\
\text { Limavady } \\
\text { Moyle }\end{array}$ \\
\hline Enniskillen/Fermanagh/ S Tyrone & $\begin{array}{l}\text { Fermanagh } \\
\frac{1}{2} \text { Strabane }\end{array}$ \\
\hline Mid Ulster & $\begin{array}{l}\text { Cookstown } \\
\text { Dungannon } \\
\text { Magherafelt } \\
\text { Omagh }\end{array}$ \\
\hline Mid and South Down & $\begin{array}{l}\text { Down } \\
\text { Newry and Mourne }\end{array}$ \\
\hline Craigavon/Armagh & $\begin{array}{l}\text { Armagh } \\
\text { Banbridge } \\
\text { Craigavon }\end{array}$ \\
\hline
\end{tabular}

We have also used population trends between 1991 and 2001 (the two census years) but results have been identical and are therefore not reported.

Unemployment: Monthly unemployment counts are provided by the UK office for National Statistics. We use the 3 month average of the counts for our purposes. Again, unemployment counts are provided for each of the council districts so that we have to recode the data according to the above 
table. We have also combined this data with constructed population trends to see whether a measure of the unemployment rate would yield different results. This is not the case.

Polarization: We use the 1991 census data to construct the share of Catholics in the total population. Our polarization measure is constructed with the help of this share and the following formula

$$
\text { polarization }=\operatorname{share}(1-\text { share }) \text {. }
$$

Hence, polarization is high if the group of Catholics and non-Catholics are the same size and low if one group is in the clear majority. ${ }^{13}$ Different measures of polarization that use the full available data on the four largest religious groups in Northern Ireland have been tested and lead to identical results.

Pre-sample deaths: Pre-sample deaths for the years 1981 and 1982 have been compiled by the same rules as the deaths data. Once the data was compiled we calculated the average quarterly amount of deaths for each region.

\footnotetext{
${ }^{13}$ See Montalvo and Reynal-Querol (2005) for a more detailed discussion of polarization measures.
} 
Appendix: Heterogeneity in Raw Violence Data

\begin{tabular}{|c|c|c|c|c|c|}
\hline VARIARIFS & (1) & (2) & (3) & (4) & (5) \\
\hline \multirow{2}{*}{ deaths } & & $-0.0180^{\star \star \star *}$ & -0.00589 & -0.0586 & $-0.0321^{* * *}$ \\
\hline & & (0.00545) & (0.00485) & (0.0401) & (0.00932) \\
\hline
\end{tabular}

deaths per capita $\quad-1598^{\star \star *} \quad 889.4$

(480.1) (892.5)

deaths

* pre-sample violence

$-0.00147^{*}$

$(0.000761)$

deaths

* polarization

$(0.175)$

deaths

* share of catholics

$0.0417^{\star \star}$

(0.0197)

$\begin{array}{lccc}\text { Observations } & 1038 & 1038 & 1038 \\ \text { Region Fixed Effects } & \text { yes } & \text { yes } & \text { yes } \\ \text { Time Fixed Effects } & \text { yes } & \text { yes } & \text { yes } \\ \text { R-squared } & 0.987 & 0.987 & 0.987 \\ \text { Number of regions } & 11 & 11 & 11\end{array}$

Standard OLS errors in parentheses (Note: not bootstrapped)

Deaths are weighed with their standard deviation.

*** $p<0.01$, ** $p<0.05$, * $p<0.1$ 
Table 1: Linear Results

$\begin{array}{llllll}(1) & (2) & (3) & (4) & \text { (5) }\end{array}$

\section{COEFFICIENT} In(houseprice) deaths $-0.189^{\star * *}$ In(houseprice) n(houseprice) In(houseprice) (0.0199) $-0.209^{\star \star \star}$ $-0.0134^{\star \star \star}$ $-0.00767^{\star \star *}$ (0.0210)

$(0.00291)$

(0.00296)

n(houseprice) (seprice)

deaths (lagged two quarters)

$-0.0188^{\star \star *}$

(0.00293)

In(unemployment)

$-0.145^{\star * \star}$

Observations

Region Fixed Effects

1038

1038

1038

1038

(0.0273)

\section{Time Fixed Effects}

no

yes

yes

yes

1038

921

Region-Specific Time Trends

OLS standard errors in parentheses, ${ }^{* \star} p<0.01,{ }^{* \star} p<0.05,{ }^{*} p<0.1$

$0.987 \quad 0.989$

Note: All explanatory variables are lagged by one quarter. Deaths are normed by the overall standard deviation of deaths.

Time Periods: 1984q4 - 2007q4 (1-5), 1987q3 - 2007q4 (6) 
Table 2: Estimation of Region-Specific Markov Chain Parameters

\begin{tabular}{lcccc} 
Region & $\begin{array}{c}\text { Mean Deaths per } \\
\text { Quarter in Conflict }\end{array}$ & $\begin{array}{c}\text { Mean Deaths per } \\
\text { Quarter in Peace }\end{array}$ & $\begin{array}{c}\text { Probability of a } \\
\text { Quarter of Conflict } \\
\text { following Conflict }\end{array}$ & $\begin{array}{c}\text { Probability of a } \\
\text { Quarter of Peace } \\
\text { following Peace }\end{array}$ \\
\hline Belfast & 8.114 & 1.334 & 0.935 & 0.956 \\
North Down & 1.114 & 0.000 & 0.268 & 0.877 \\
Lisburn & 1.333 & 0.000 & 0.288 & 0.799 \\
East Antrim & 1.431 & 0.000 & 0.074 & 0.851 \\
Londonderry/Strabane & 1.811 & 0.111 & 0.962 & 0.965 \\
Antrim/Ballymena & 0.986 & 0.000 & 0.000 & 0.894 \\
Coleraine/Limavady N Coast & 1.648 & 0.000 & 0.000 & 0.926 \\
Enniskillen/Fermanagh/ S Tyrone & 1.686 & 0.000 & 0.765 & 0.880 \\
Mid Ulster & 3.661 & 0.000 & 0.746 & 0.857 \\
Mid and South Down & 2.388 & 0.093 & 0.967 & 0.969 \\
Craigavon/Armagh & 3.273 & 0.266 & 0.643 & 0.844
\end{tabular}

Estimates obtained through application of the EM Algorithm discussed in Hamilton (1990) 
(5)

\section{COEFFICIENT} In(houseprice)

present value of killings

$(r=5 \%)$, see equation 2

$-0.0607^{\star \star *}$

In(houseprice) In(houseprice)

In(houseprice)

(0.00895)

$-0.0579 * \star \star$

-0.0410 ***

ent value of killings

$(r=1 \%)$, see equation 2

villing

$(r=5 \%)$ lagged two quarters

$-0.0599 * \star *$

\section{$(0.00904)$}

In(unemployment)

$$
\begin{aligned}
& -0.145^{\star \star \star} \\
& (0.0271)
\end{aligned}
$$

Observations

Region Fixed Effects

1038

1038

1038

921

1038

Time Fixed Effects

yes

yes

yes

yes

yes

yes

yes

yes

yes

yes

Region-Specific Time Trend

no

R-squared

0.987

0.987

0.987

0.987

0.989

Bootstrapped standard errors (1000 iterations) in parentheses, *** $p<0.01$, ${ }^{* *} p<0.05,{ }^{*} p<0.1$

Note: All explanatory variables are lagged by one quarter. Present values are normed by their standard deviation.

Time Periods: 1984q4 - 2007q4 (1-3, 5), 1987q3 - 2007q4 (4) 
Table 4: Heterogeneity

(1)

(2)

(3)

(4)

(5)

\section{COEFFICIENT} n(houseprice) In(houseprice)

present value of killings ( $r=5 \%$ )

per capita

$-0.0436^{\star \star *} \quad-0.00121$

(0.00713) (0.0148)

present value of killings $(r=5 \%)$,

see equation 2

$\begin{array}{llll}-0.0594^{\star * \star} & -0.0750^{\star * *} & -0.0510^{\star *} & -0.170 \\ (0.0183) & (0.0199) & (0.0234) & (0.338)\end{array}$

present value of killings ( $r=5 \%$ )

* mean of pre-sample violence

0.0176

$(0.0222)$

present value of killings $(r=5 \%)$

* share of catholics

$-0.00938$

$(0.0202)$

present value of killings ( $r=5 \%$ )

* polarization

Observations

Region Fixed Effects

Time Fixed Effects

Region-Specific Time Trend

R-squared

$\begin{array}{cc}1038 & 1038 \\ \text { yes } & \text { yes } \\ \text { yes } & \text { yes } \\ \text { no } & \text { no } \\ 0.987 & 0.987\end{array}$

1038

1038

1038

Bootstrapped standard errors (1000 iterations) in parentheses, ${ }^{* \star *} p<0.01,{ }^{* *} p<0.05,{ }^{*} p<0.1$

Notes: Explanatory variables are normed by their respective overall standard deviation and lagged by one quarter.

Time Periods: 1984q4 - 2008q4 
(1) (2) (3) (4)

(5)

\begin{tabular}{lcc} 
COEFFICIENT & $\operatorname{In}$ (houseprice) & $\operatorname{In}$ (houseprice) \\
\hline conflict (present value at $r=5 \%)$ & $-0.00804^{\star \star \star}$ & $-0.00953^{\star \star \star}$ \\
& $(0.00136)$ & $(0.00182)$
\end{tabular}

present value of killings

$(r=5 \%)$, see equation 2

$-0.0673^{\star \star *}$

(0.0115)

boundary to Belfast

* present value (Belfast)

$0.0269^{\star \star \star}$

(0.00728)

$-0.0267$

(0.0542)

$-0.0226$

(0.0236)

$-0.0291$

(0.0318)

$-0.0792^{\star * *}$

(0.0152)

boundary to Mid/South Down

* present value

$$
\begin{array}{ll}
-0.0182^{\star \star \star} & -0.0143^{\star \star \star} \\
(0.00275) & (0.00313)
\end{array}
$$

deaths

(single index EM estimate)

In(unemployment)

$-0.242^{\star \star *}$

(0.0473)

$-0.129^{\star \star \star}$

$-0.0283$

Observations

1038

921

1038

1038

921

Region Fixed Effects

yes

yes

yes

yes

yes

Time Fixed Effects

yes

yes

yes

yes

yes

Region-Specific Time Trend

no

yes

no

no

no

R-squared

0.987

0.988

0.988

0.987

0.986

Bootstrapped standard errors (1000 iterations) in parentheses, ${ }^{* *} p<0.01,{ }^{* *} p<0.05,{ }^{*} p<0.1$ Notes: All violence variables are normed by their respective overall standard deviation.

Time Periods: 1984q4 - 2008q4 (1, 3, 4), 1987q3 - 2008q4 $(2,5)$ 


\begin{tabular}{|c|c|c|c|c|c|c|c|c|}
\hline & \multirow{2}{*}{$\begin{array}{c}\text { Present Value of } \\
\text { Violence }(r=5 \%) \text { in } \\
\text { Conflict } \\
\end{array}$} & \multirow{2}{*}{$\begin{array}{r}\text { Present Value of } \\
\text { Violence }(r=5 \%) \\
\text { during Peace Time }\end{array}$} & \multicolumn{2}{|c|}{$\begin{array}{l}\text { Impact of Conflict on Houseprices in } \\
\text { Percent ( } 95 \% \text { Confidence Intervall) }\end{array}$} & \multirow{2}{*}{$\begin{array}{c}\text { Present Value of } \\
\text { Violence }(r=1 \%) \text { in } \\
\text { Conflict }\end{array}$} & \multirow{2}{*}{$\begin{array}{c}\text { Present Value of } \\
\text { Violence }(r=1 \%) \\
\text { during Peace Time }\end{array}$} & \multicolumn{2}{|c|}{$\begin{array}{l}\text { Impact of Conflict on Houseprices in } \\
\text { Percent (95\% Confidence Intervall) }\end{array}$} \\
\hline & & & lower bound & upper bound & & & lower bound & upper bound \\
\hline Belfast & 4.67 & 2.82 & 8.02 & 14.54 & 4.01 & 3.50 & 7.74 & 13.84 \\
\hline North Down & 0.19 & 0.13 & 0.23 & 0.42 & 0.16 & 0.14 & 0.18 & 0.32 \\
\hline Lisburn & 0.30 & 0.24 & 0.26 & 0.47 & 0.28 & 0.27 & 0.20 & 0.35 \\
\hline East Antrim & 0.22 & 0.17 & 0.24 & 0.43 & 0.19 & 0.18 & 0.18 & 0.33 \\
\hline Londonderry/Strabane & 1.13 & 0.53 & 2.61 & 4.73 & 0.95 & 0.76 & 2.84 & 5.08 \\
\hline Antrim/Ballymena & 0.12 & 0.08 & 0.16 & 0.29 & 0.09 & 0.09 & 0.12 & 0.22 \\
\hline Coleraine/Limavady N Coast & 0.16 & 0.09 & 0.28 & 0.50 & 0.12 & 0.10 & 0.21 & 0.38 \\
\hline Enniskillen/Fermanagh/S Tyrone & 0.62 & 0.44 & 0.78 & 1.42 & 0.55 & 0.51 & 0.64 & 1.14 \\
\hline Mid Ulster & 1.38 & 1.04 & 1.47 & 2.67 & 1.25 & 1.17 & 1.25 & 2.23 \\
\hline Mid and South Down & 1.51 & 0.63 & 3.79 & 6.86 & 1.24 & 0.96 & 4.27 & 7.65 \\
\hline Craigavon/Armagh & 1.20 & 0.97 & 1.00 & 1.82 & 1.14 & 1.09 & 0.73 & 1.31 \\
\hline Average & 1.05 & 0.65 & 1.71 & 3.10 & 0.91 & 0.80 & 1.67 & 2.98 \\
\hline Average (population weights) & 1.58 & 0.97 & 2.63 & 4.77 & 1.36 & 1.19 & 2.56 & 4.58 \\
\hline
\end{tabular}

Note: Present values are normed by their overall standard deviation. Population weights are by 1991 population (see appendix for details). 
Table 7: Comparison of Estimates

\begin{tabular}{|c|c|c|c|c|c|c|}
\hline & \multirow{2}{*}{\multicolumn{2}{|c|}{$\begin{array}{l}\text { Present Value Estimates } \\
\text { Impact of Conflict on Houseprices in } \\
\text { Percent (95\% Confidence Intervall) }\end{array}$}} & \multirow{3}{*}{$\begin{array}{c}\text { Estimated Mean } \\
\text { Level of Violence in } \\
\text { Conflict }\end{array}$} & \multicolumn{3}{|c|}{ Raw Violence Data Estimates } \\
\hline & & & & \multirow{2}{*}{$\begin{array}{c}\text { Estimated Mean } \\
\text { Level of Violence } \\
\text { during Peace Time }\end{array}$} & \multicolumn{2}{|c|}{$\begin{array}{l}\text { Impact of Conflict on Houseprices in } \\
\text { Percent (95\% Confidence Intervall) }\end{array}$} \\
\hline & lower bound & upper bound & & & lower bound & upper bound \\
\hline Belfast & 8.02 & 14.54 & 8.114 & 1.334 & 2.22 & 5.50 \\
\hline North Down & 0.23 & 0.42 & 1.114 & 0.000 & 0.36 & 0.90 \\
\hline Lisburn & 0.26 & 0.47 & 1.333 & 0.000 & 0.44 & 1.08 \\
\hline East Antrim & 0.24 & 0.43 & 1.431 & 0.000 & 0.47 & 1.16 \\
\hline Londonderry/Strabar & 2.61 & 4.73 & 1.811 & 0.111 & 0.56 & 1.38 \\
\hline Antrim/Ballymena & 0.16 & 0.29 & 0.986 & 0.000 & 0.32 & 0.80 \\
\hline Coleraine/Limavady & 0.28 & 0.50 & 1.648 & 0.000 & 0.54 & 1.34 \\
\hline Enniskillen/Fermana! & 0.78 & 1.42 & 1.686 & 0.000 & 0.55 & 1.37 \\
\hline Mid Ulster & 1.47 & 2.67 & 3.661 & 0.000 & 1.20 & 2.97 \\
\hline Mid and South Down & 3.79 & 6.86 & 2.388 & 0.093 & 0.75 & 1.86 \\
\hline Craigavon/Armagh & 1.00 & 1.82 & 3.273 & 0.266 & 0.98 & 2.44 \\
\hline Average & 1.71 & 3.10 & 2.49 & 0.16 & 0.76 & 1.89 \\
\hline
\end{tabular}

Note: Present values are normed by their overall standard deviation 
Table 8: Economic Significance - Single Index Model

\begin{tabular}{lcccc} 
& \multicolumn{2}{c}{$\begin{array}{c}\text { Mean of Deaths in } \\
\text { Conflict } \\
\text { Index }\end{array}$} & $\begin{array}{c}\text { Mean of Deaths } \\
\text { during Peace Time } \\
\text { (Single Index) }\end{array}$ & \multicolumn{2}{c}{$\begin{array}{c}\text { Impact of Conflict on Houseprices in } \\
\text { Percent (95\% Confidence Intervall) } \\
\text { lower bound }\end{array}$} & $\begin{array}{l}\text { upper bound } \\
\text { Belfast }\end{array}$ \\
T.00 & 1.02 & $\mathbf{7 . 6 6}$ & $\mathbf{1 4 . 1 0}$ \\
North Down & 0.19 & 0.19 & $\mathbf{0 . 0 0}$ & $\mathbf{0 . 0 0}$ \\
Lisburn & 0.50 & 0.00 & $\mathbf{0 . 6 5}$ & $\mathbf{1 . 1 9}$ \\
East Antrim & 0.00 & 0.00 & $\mathbf{0 . 0 0}$ & $\mathbf{0 . 0 0}$ \\
Londonderry/Strabane & 1.65 & 0.00 & $\mathbf{2 . 1 1}$ & $\mathbf{3 . 8 9}$ \\
Antrim/Ballymena & 0.07 & 0.07 & $\mathbf{0 . 0 0}$ & $\mathbf{0 . 0 0}$ \\
Coleraine/Limavady N Coast & 0.21 & 0.00 & $\mathbf{0 . 2 7}$ & $\mathbf{0 . 5 0}$ \\
Enniskillen/Fermanagh/ S Tyrone & 1.20 & 0.00 & $\mathbf{1 . 5 4}$ & $\mathbf{2 . 8 3}$ \\
Mid Ulster & 2.76 & 0.00 & $\mathbf{3 . 5 4}$ & $\mathbf{6 . 5 1}$ \\
Mid and South Down & 2.22 & 0.00 & $\mathbf{2 . 8 4}$ & $\mathbf{5 . 2 4}$ \\
Craigavon/Armagh & 1.89 & 0.00 & $\mathbf{2 . 4 2}$ & $\mathbf{4 . 4 6}$ \\
\hline Average & 1.61 & 0.12 & $\mathbf{1 . 9 1}$ & $\mathbf{3 . 5 2}$ \\
Average (population weights) & 2.41 & 0.23 & $\mathbf{2 . 8 0}$ & $\mathbf{5 . 1 5}$
\end{tabular}


Table 9: Summary Statistics

\begin{tabular}{|c|c|c|c|c|}
\hline data & Mean & Std. Deviation & Min & $\operatorname{Max}$ \\
\hline houseprice & 77932.2 & 58232.4 & 23222 & 292931 \\
\hline unemployment count & 6009.417 & 5353.389 & 1000.333 & 34696.67 \\
\hline number of deaths & 0.9082251 & 2.353189 & 0 & 29 \\
\hline population & 143439.6 & 67169.43 & 72033 & 340036 \\
\hline polarization & 0.2012915 & 0.0496568 & 0.090681 & 0.2476119 \\
\hline $\begin{array}{l}\text { pre-sample deaths mean } \\
\text { constructed variables }\end{array}$ & 1.829545 & 2.572467 & 0 & 8.114 \\
\hline $\begin{array}{l}\text { present value }(r=5 \%) \\
\text { see equation } 2\end{array}$ & 19.28806 & 23.97179 & 1.898856 & 112.0985 \\
\hline $\begin{array}{l}\text { present value }(r=1 \%) \\
\text { see equation } 2\end{array}$ & 91.93297 & 109.5117 & 9.361521 & 440.3561 \\
\hline
\end{tabular}


Figure 1: Total Quarterly Deaths in Northern Ireland

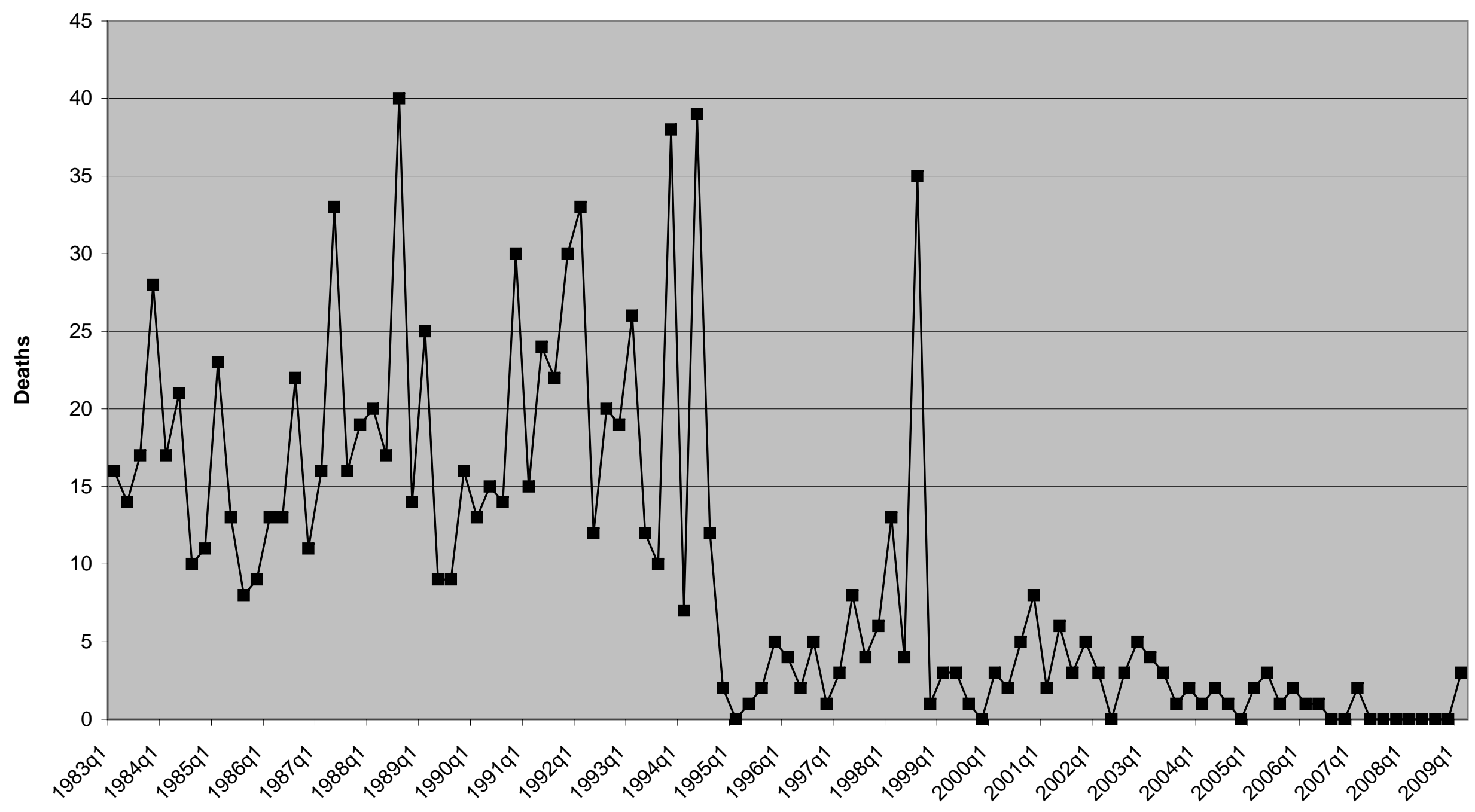



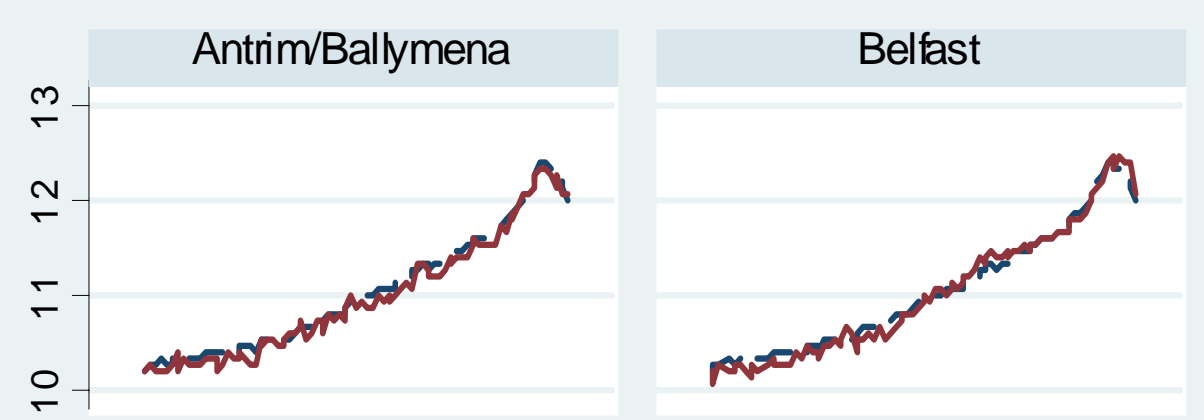

Coleraine/Limavady N Coast

\section{Craigavon/Armagh}

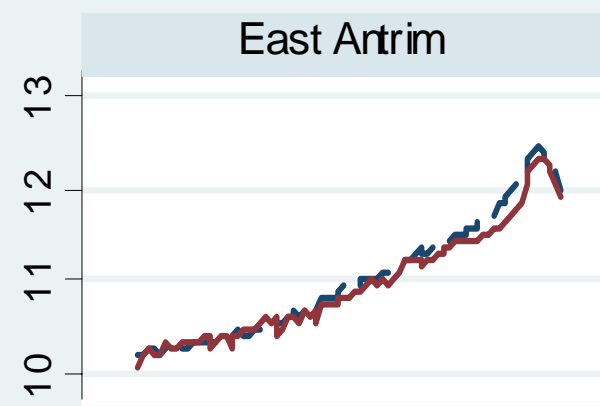

Enniskillen/Fermanagh/ STyrone
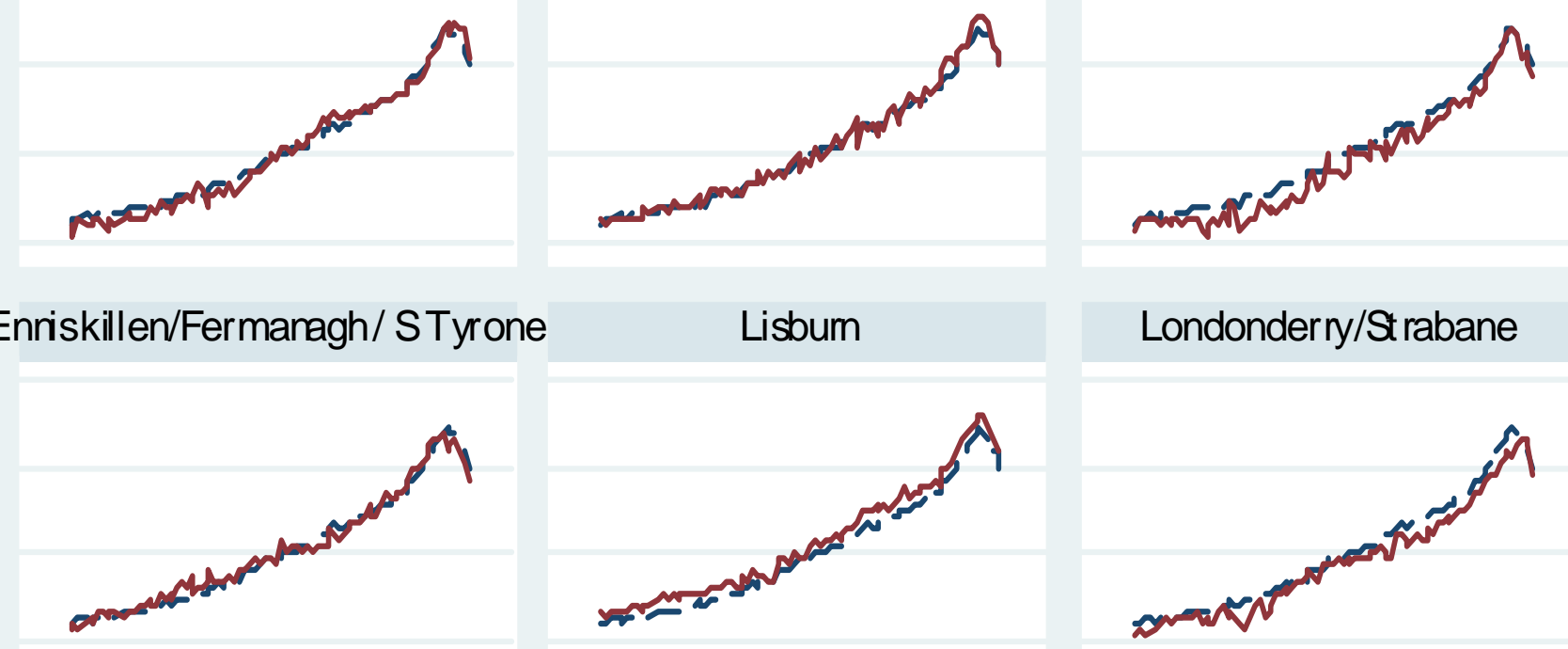

\section{Londonderry/Strabane}
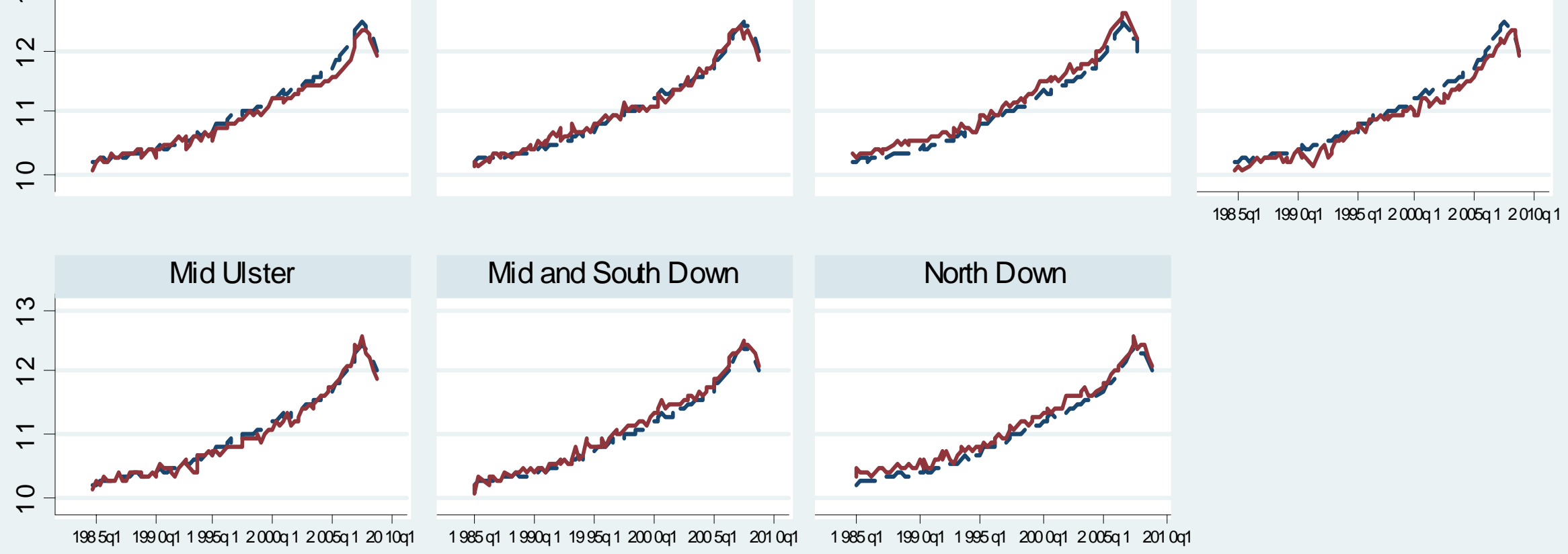

time

$$
\text { -- - - In(housing price mean) }
$$

$$
\text { In (housing price) }
$$

Figure 2 
5 Year Average of Killings in Northern Ireland (1985q1-1989q4)

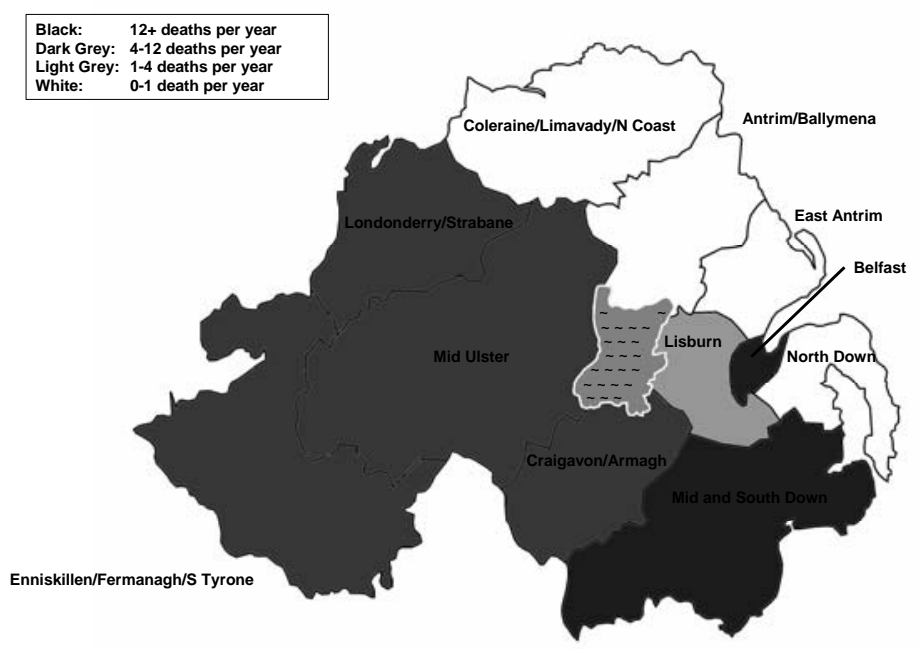

5 Year Average of Killings in Northern Ireland (2000q1-2004q4)

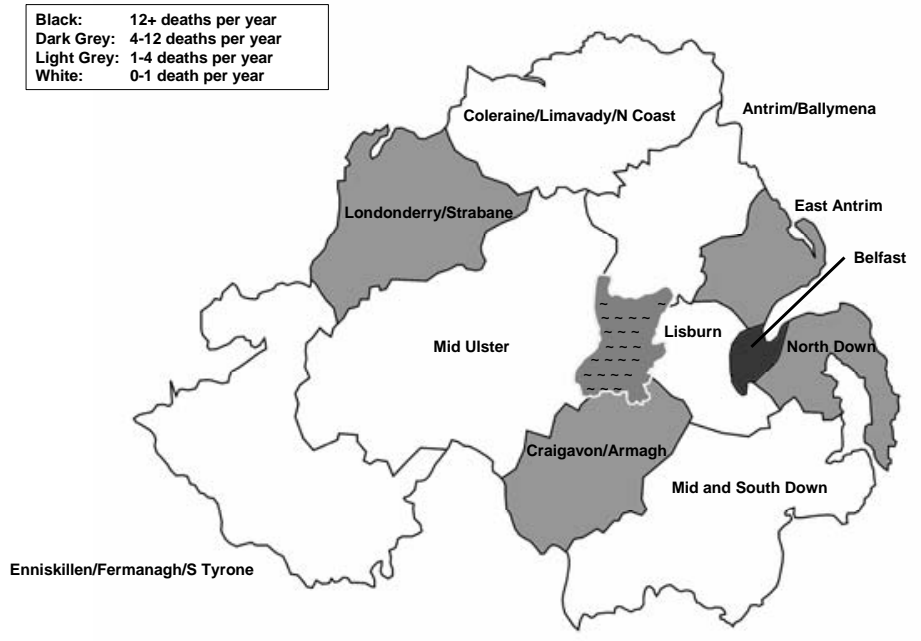

5 Year Average of Killings in Northern Ireland (1995q1-1999q4)

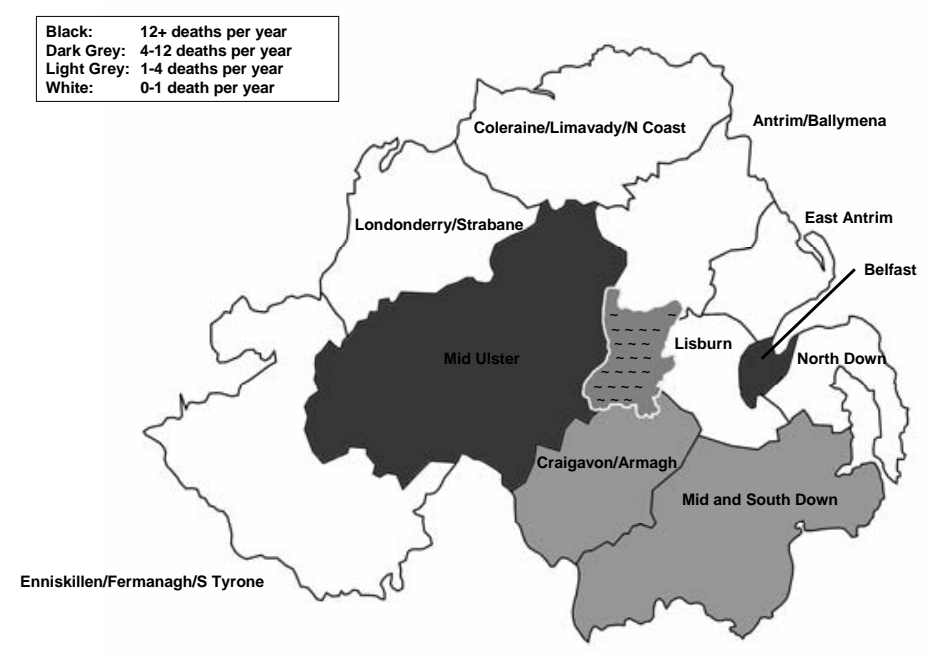

5 Year Average of Killings in Northern Ireland (2005q1-2009q1)

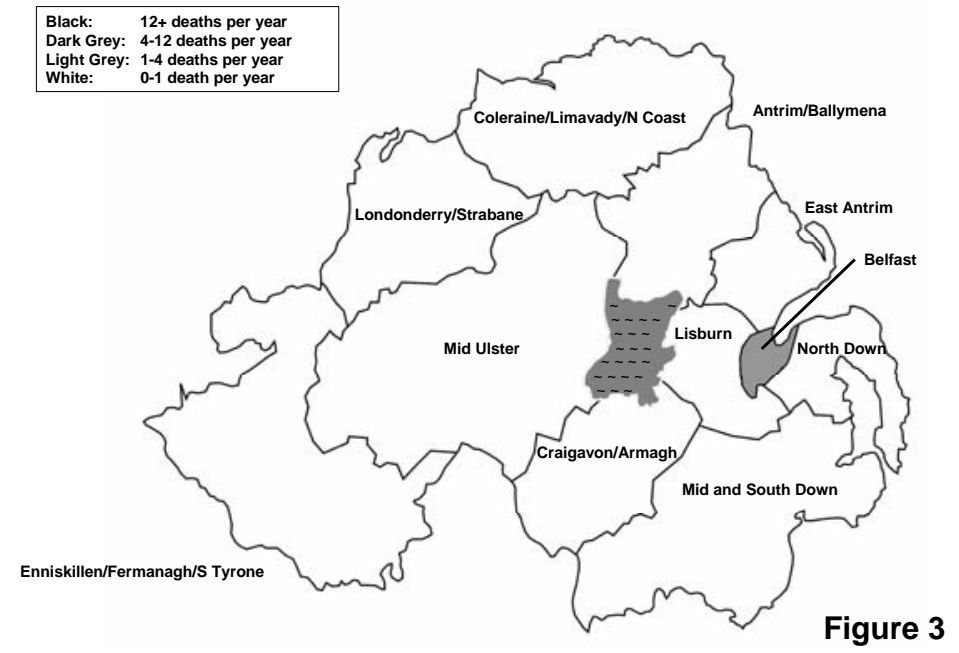


Figure 4: Belfast Quarterly Deaths and Fitted Values

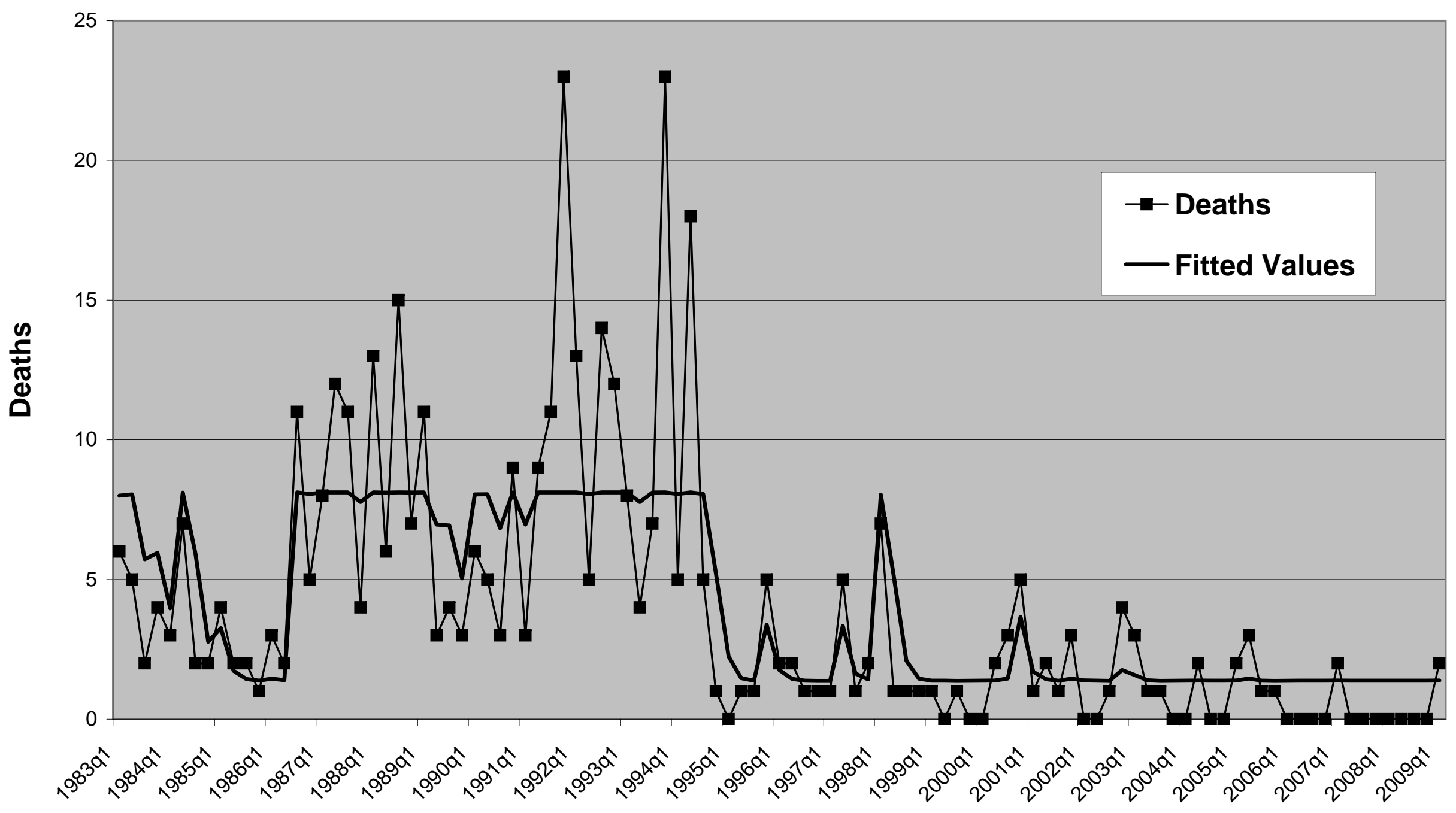


Figure 5: Londonderry/Strabane Quarterly Deaths and Fitted Values

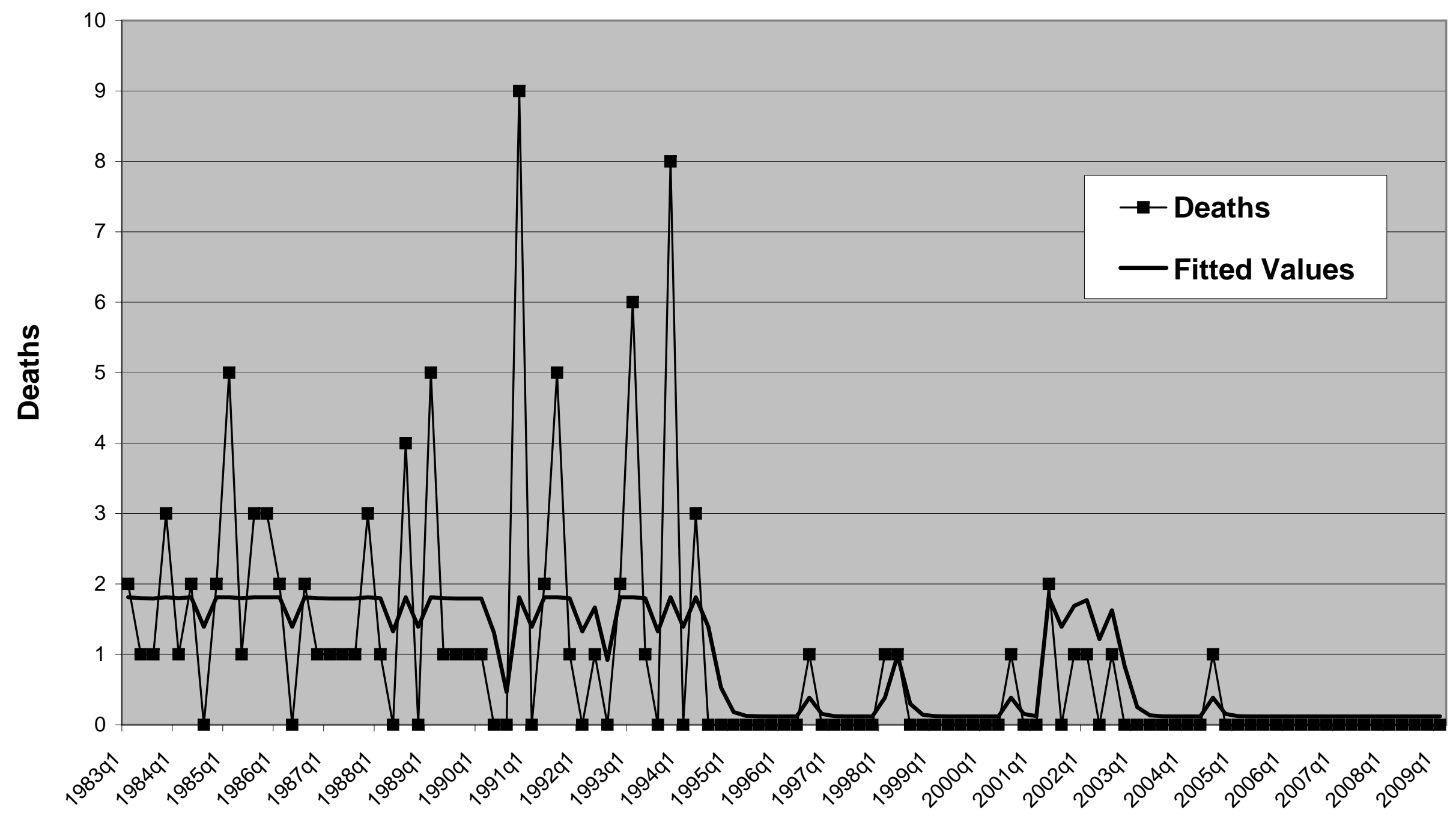


Figure 6: Lisburn Quarterly Deaths and Fitted Values

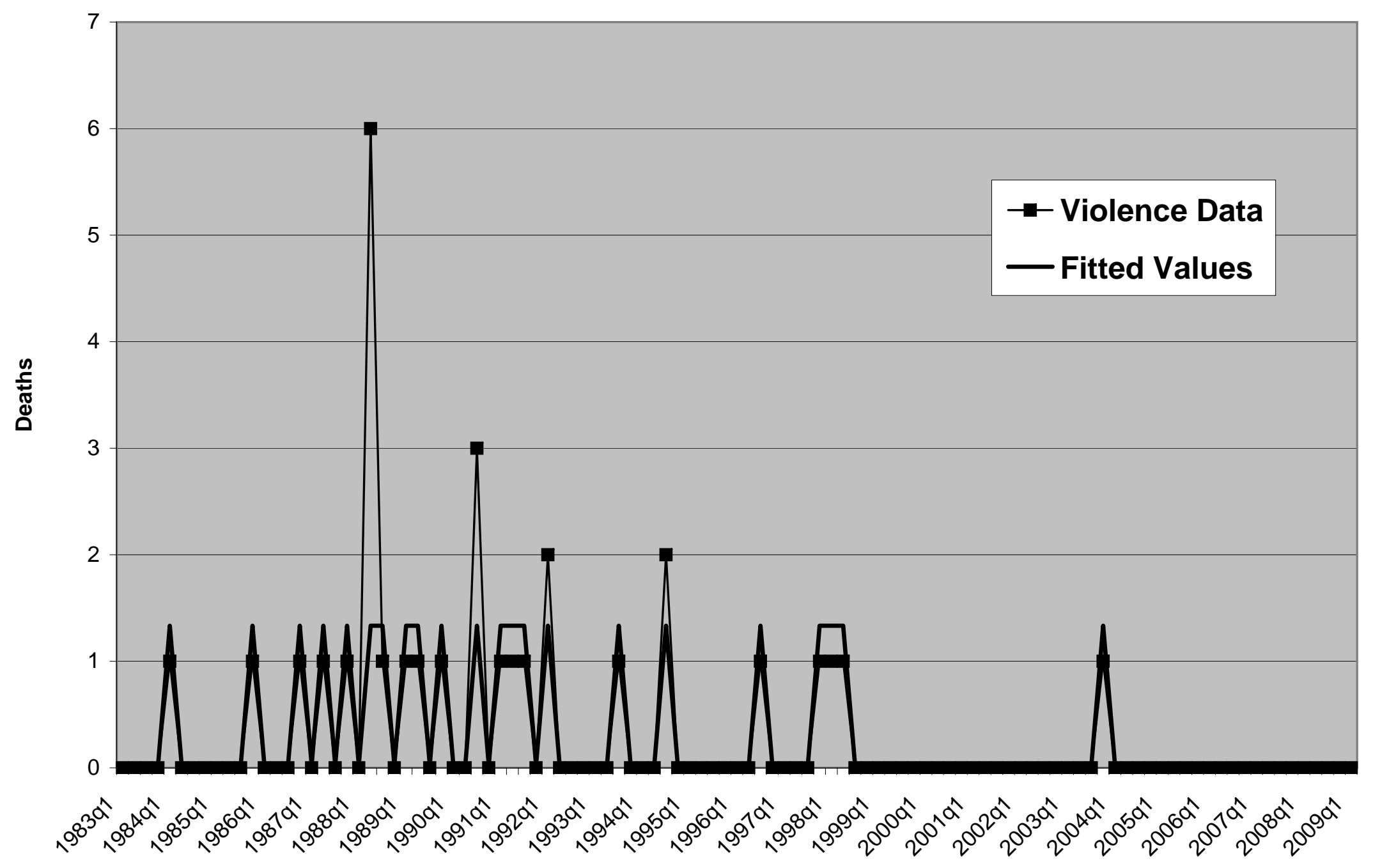


Figure 7: Total Quarterly Deaths in Northern Ireland and EM Fitted Values

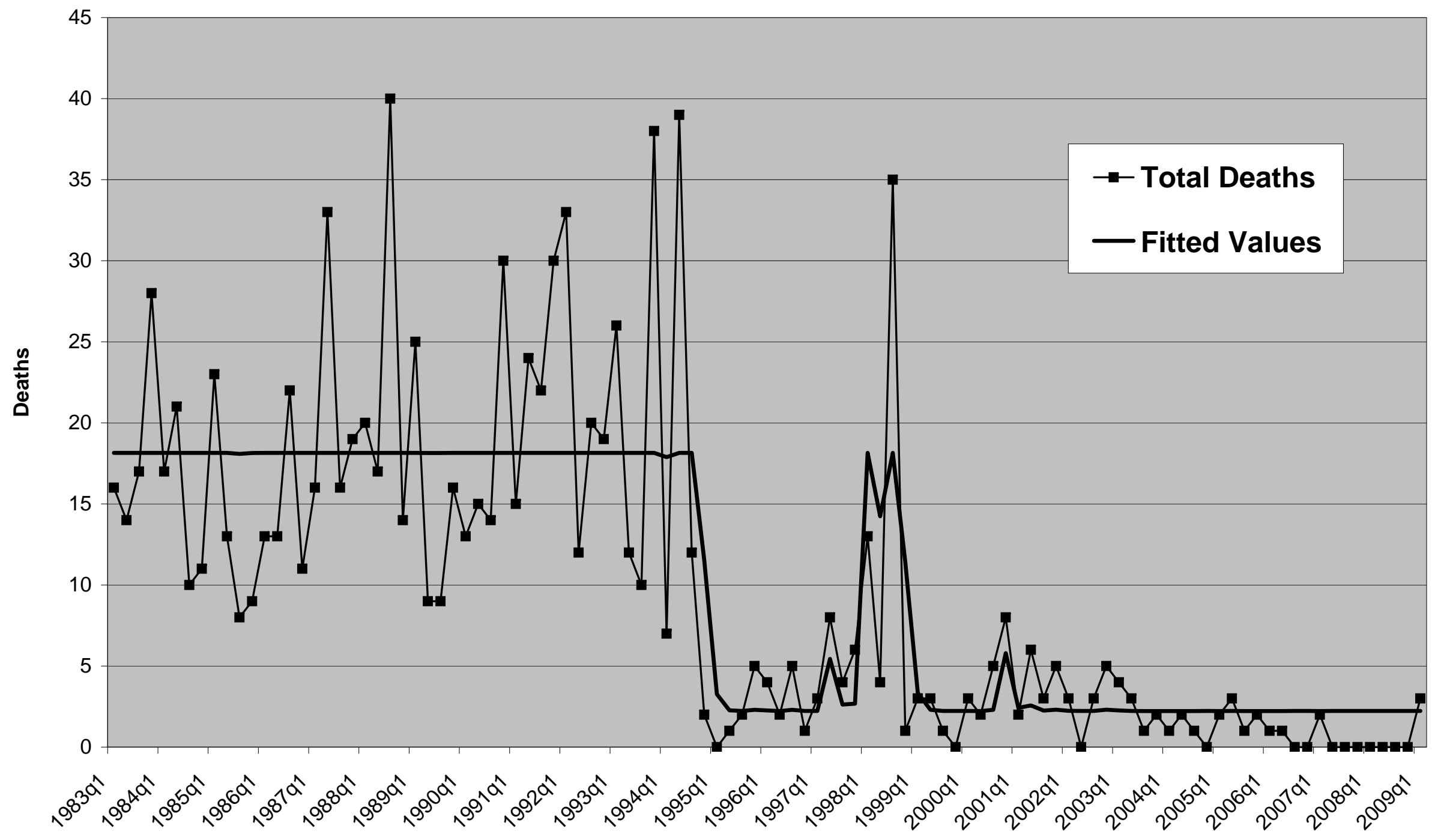


Figure 8: Londonderry/Strabane Comparison of Fitted Values

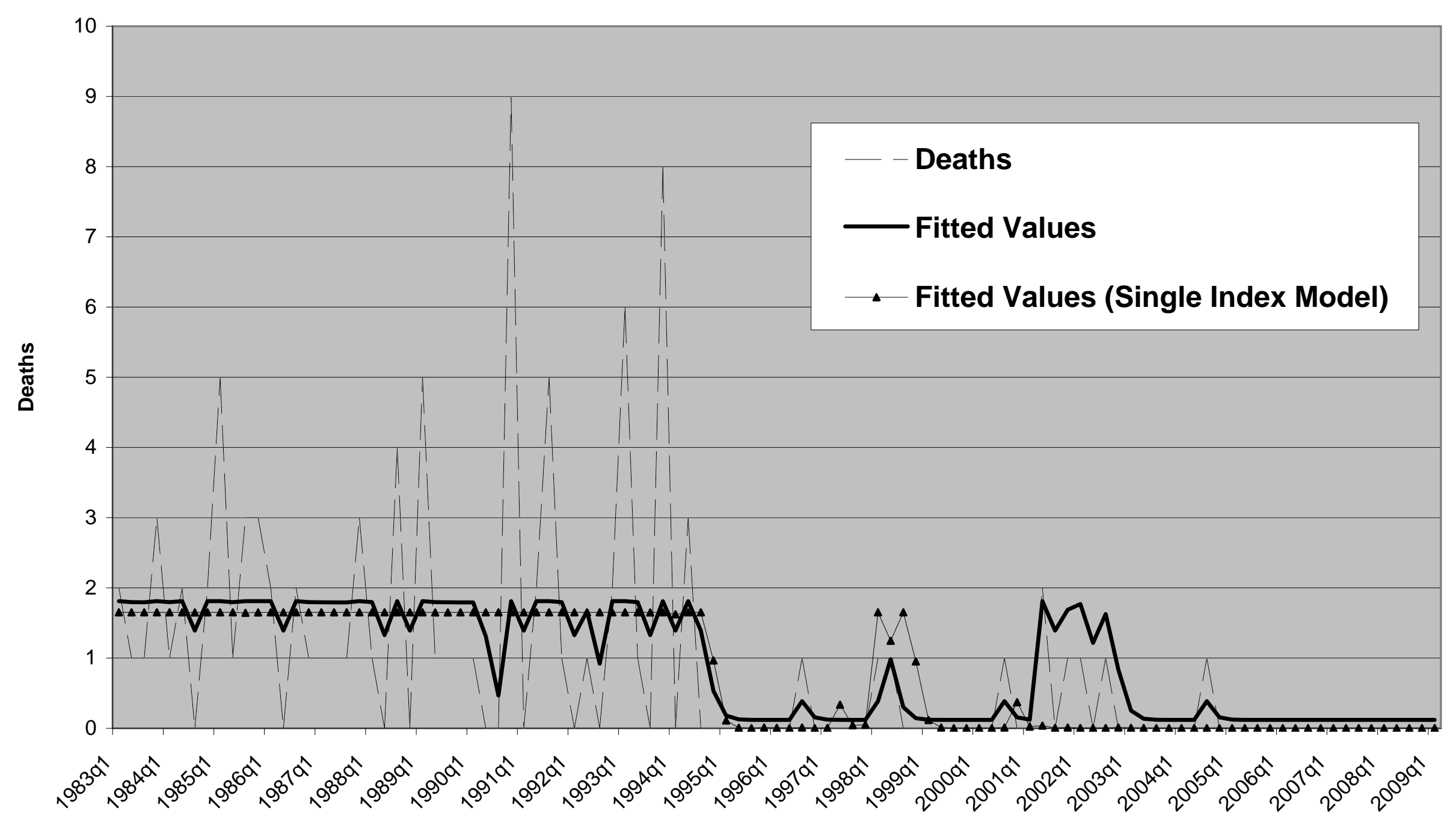

